NBSIR 75-925

\title{
FINAL SUMMARY REPORT STUDY OF THE NATIONAL MEASUREMENT SYSTEM 1972.75
}

Raymond C. Sangster

Office of the Deputy Director Institute for Basic Standards National Bureau of Standards Boulder, Colorado 80302

QC er 1976

100

.456

no. 75.926

1976

C. 2 


\section{FINAL SUMMARY REPORT}

\section{STUDY OF THE NATIONAL MEASUREMENT SYSTEM 1972.75}

Raymond C. Sangster

Office of the Deputy Director Institute for Basic Standards Hational Bureau of Standards Boulder, Colorado 80302

\section{December 1976}

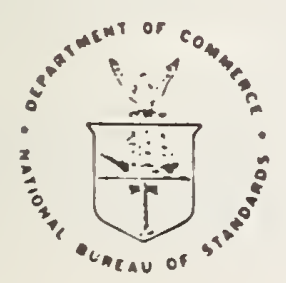

U.S. DEPARTMENT OF COMMERCE, Elliot L. Richardson, Secretary Edward $O$. Vetter, Under Secretary Dr Betsy Ancker-Johnson, Assistant Secretary for Science and Technology NATIONAL BUREAU OF STANDARDS, Ernest Ambler, Acting Director 


\title{
FOREWORD
}

The concept of a National Measurement System has, for many years, provided a useful focus for the considerations important to physical measurements in our technology intensive economy. Dr. R. D. Huntoon, in his October 6, 1967, article in Science, emphasized the basis for a systems viewpoint in interrelated measurements activities and the idea has continued to evolve. Today, we think of the U.S. National Measurement System in terms of all the intellectual, functional and institutional activities which enter into measurements throughout our society. Moreover, we seek to understand more completely the structural nature of this system and its architectural needs.

There have been a number of approaches to the study of our national system for physical measurements. The present series of studies was initiated in 1972 by Dr. Ernest Ambler, then Director of the Institute for Basic Standards. It was Dr. Ambler's purpose to organize the essential information necessary for the effective management of NBS resources and to promote the direct interaction between IBS staff members and the communities of users they serve.

This document reflects the results of the intensive studies carried out during the period from 1972 - 1975. It is important to recognize that the National Measurement System is extremely complex having widely distributed elements and impacts. The detailed analysis of this system is well beyond the state-of-the-art of econometric modeling, and therefore, any study, no matter how intensive, is necessarily incomplete. Nevertheless, the information which is now in hand provides an important addition to our capability for planning and implementing the programs of IBS. It also represents a growing foundation upon which we can continue our efforts to build a more effective structure.

\author{
A. 0. McCoubrey \\ Director, Institute for Basic Standards \\ National Bureau of Standards \\ August 1976
}




\section{PREFACE}

The 1972-75 Study of the National Measurement System by the NBS Institute for Basic Standards has been a massive effort involving many people in all divisions of the Institute. The information compiled in this document is one of the results of this effort, and could never have been developed without the contributions of a large number of knowledgeable individuals.

The Study was organized around a central coordinator and a group of "National Measurement System Study representatives" from the technical divisions of the Institute. The initial central coordinator was Dr. James R. Seed, a Presidential Interchange Executive from the Dow Chemical Company, on temporary assignment to the National Bureau of Standards. Dr. Seed was responsible for the initial formulation of the tactical plans for this Study, and carried the project through to the generation of a complete set of comprehensive reports on the structure and operation of the various portions of the System, in December 1973. In August 1974, I took over the central coordinator position, and worked with the Study representatives from the divisions of the Institute, to round out the pattern of the Study and to develop the final reports which are being issued by NBS for the different areas of measurement interest. Dr. David T. Goldman, Deputy Director of this NBS Institute, provided direct managerial guidance and made many contributions, both broad and specific, to all aspects of this study.

Any summary report of the efforts of many contributing authors is bound to involve use of the words of those authors without explicit acknowledgement. This has certainly occurred in this document, especially in sections 3.4 and 3.5 . At least the following individuals must be acknowledged as coauthors of these sections of the report: Howard E. Morgan, Barry W. Poulson (University of Colorado), Allan S. Risley, John W. Lazar, John D. Ramboz, Russel1 D. Young, James R. Whetstone, Donald E. Marlowe, William C. Haight, Peter L. M. Heydemann, James F. Schooley, Arnold Wexler, Max Klein, Thomas M. Flynn, Norman B. Belecki, Francis X. Ries, Paul A. Hudson, David S. Pallett, Henry J. Kostkowski, William H.Venable,Jr., William R. Ott, Dennis A. Swyt, Robert J. Mahler, Arthur V. Phelps, John W.Cooper, Cedric J. Powell and Randall S. Caswell (all of NBS except where noted parenthetically as otherwise). In addition, these contributing authors also had collaborating authors, so that the ultimate origin of a particularly apt formulation of a specific point in sections 3.4 and 3.5 could well trace to still some other individual. The original reports from which the material in these sections was taken are cited and listed in the References section.

No report of this sort could be generated without many hours spent at the typewriter. This one would not exist without the competent and unstinting efforts of my secretaries and everyone else whom they could obtain to support them, and I wish to thank them, one and all: Carol Ciufolo, Marty Tyner, Pamela Killian, Angela Digiallonardo, Sheila Aaker, Sue Randolph, Nancy Mills, Kay Stephenson, Shirley Deeg, and Doris Schaffner.

We trust that the availability of this document will be useful to many readers who need only an overview of the results of our Study of the National Measurement System. For those who want more detailed information about any part of this study, we have provided a "Report Request Card" at the back of this document, which can be used to request the specific reports wanted. 
FOREWORD.

EXECUTIVE SUMMARY

1. INTRODUCTION. . . . . . . . . . . . . . . . . . . . . .

1.1 Concept of a National Measurement System ............... 3

1.2 Background of Present Study. . . . . . . . . . . . . . . . . . 3

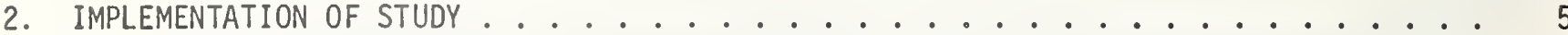

2.1 Organization of Study. . . . . . . . . . . . . . . . . . 5

2.2 Approaches to Study. . . . . . . . . . . . . . . . . . . 6

2.3 Techniques for Observing the System. . . . . . . . . . . . . . . 6

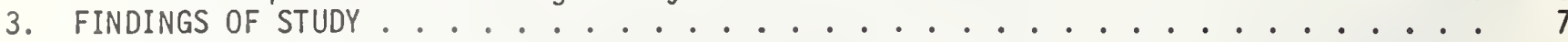

3.1 Model of the System. . . . . . . . . . . . . . . . . . . 7

3.2 Status of the System . . . . . . . . . . . . . . . . . . . 9

3.3 Trends of the System . . . . . . . . . . . . . . . . . . . . 9 9

3.3.1 Increased Complexity . . . . . . . . . . . . . . . . . . . . 9 9

3.3.2 Increased Integration of the System. . . . . . . . . . . . . . 10

3.3.3 Improved Quality Control in the System ............... 10

3.3.4 Improved Information Resources for the System. . . . . . . . . . . 11

3.3.5 Automation of Measurements . . . . . . . . . . . . 11

3.3 .6 Metrication. ............................. 11

3.3.7 Science. . . . . . . . . . . . . . . . . . . . 12

3.4 Economic Analysis of the National Measurement System . . . . . . . . . . . 12

3.5 Assessments by Microstudies of Major System Trends and Needs; Programmatic Impacts of the Study ...................... 13

3.5.1 Time and Frequency ..................... . . . . 13

3.5.2 Length and Related Dimensionai Measurements. . . . . . . . . . 14

3.5.3 Vibration and Shock. . . . . . . . . . . . . . . . . 14

3.5.4 Surface Finish . . . . . . . . . . . . . . . . . 14

3.5.5 Mass, Volume, and Density. . . . . . . . . . . . . . . 15

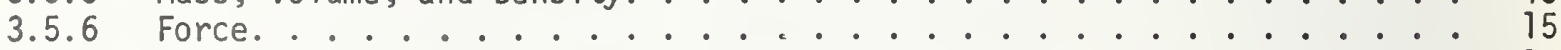

3.5.7 Fluid Flow . . . . . . . . . . . . . . . . . 15

3.5.8 Pressure ....................... 16

3.5.9 Temperature. . . . . . . . . . . . . . . 17

3.5.10 Humidity and Moisture.................... . . . 18

3.5.11 Thermodynamic Properties of Fluids. . . . . . . . . . . . . . 18

3.5.12 Cryogenics . . . . . . . . . . . . . . . . . . . 19

3.5.13 Electricity. . . . . . . . . . . . . . . . . 20

3.5.14 Electromagnetics .................... 21

3.5.15 Medical Ultrasonics. . . . . . . . . . . . . . . 21

3.5.16 Acoustics. . . . . . . . . . . . . . . . . . 21

3.5.17 Radiometry and Photometry. . . . . . . . . . . . . . . 22

3.5.18 Spectrophotometry. . . . . . . . . . . . . . . . . . 23

3.5.19 Far U1traviolet Radiometry . . . . . . . . . . . . . . 24

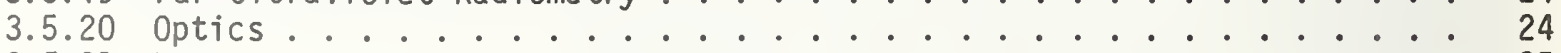

3.5.21 Lasers . . . . . . . . . . . . . . . . . . . . . . 25

3.5.22 Physical Properties of Atoms and Molecules . . . . . . . . . . . 26

3.5.23 Surface Properties . . . . . . . . . . . . . . . . 26

3.5.24 Ionizing Radiation . . . . . . . . . . . . . . . . . 27

4. SUMMARY AND CONCLUSIONS . . . . . . . . . . . . . . . . . . . . 31

REFERENCES. . . . . . . . . . . . . . . . . . . . . 35

\section{LIST OF TABLES}

Table 1 .

Table 2.

Table 3.

Table 4.

Table 5 .
Techniques used for observing the National Measurement System. . . . . . 6 Realized measurement accuracies. . . . . . . . . . . . . . . 8 Examples of Federal regulatory agencies. . . . . . . . . . . . . 9 9 Measurement intensity of principal using industries, 1963. . . . . . . 12 Economic growth of measurement-intensive industries. . . . . . . . . 12 


\title{
FINAL SUMMARY REPORT \\ STUDY OF THE NATIONAL MEASUREMENT SYSTEM
}

\author{
Raymond C. Sangster \\ Institute for Basic Standards \\ National Bureau of Standards
}

December 1976

\section{EXECUTIVE SUMMARY}

The National Measurement System consists of all of the activities and mechanisms that provide physical measurement data to allow creation of the objective, quantitative knowledge required by our society.

In 1972, the Assistant Secretary of Commerce for Administration directed the preparation of a study of "the NBS standards of measurement to determine if their accuracy is sufficient for the needs of U.S. industry." This request led to initiation of a threeyear study of the National Measurement System for the purpose of developing answers in depth to the questions posed. The internal motivation for the activity was to:

1. Provide management with enough information to alzocate limited resources to most timely, significant programs.

2. Assist in obtaining our resources by demonstrating clear concept of responsibilities...

3. Motivate our own people to improve the management of public funds spent on technological programs.

Implementation involved a macroeconomic study of the cost of measurements in our economy and a series of microstudies in the following technical areas:

Time \& frequency Length \& related dimensional measurements Vibration and shock Surface finish Mass, volume \& density Force

Fluid flow

Pressure

Temperature

Humidity \& moisture

Thermodynamic properties Cryogenics

Electricity

Electromagnetics

Medical ultrasonics

Acoustics

Radiometry \& photometry

Spectrophotometry

Far ultraviolet

Optics radiometry

Lasers

Physical properties of atoms \& molecules

Ionizing radiation

The structure of the system has been depicted by a model with five levels:

I. The conceptual system, the intellectual foundation that defines the measurement quantities and units.

II. The basic technical infrastructure that provides the tools and techniques and agreements that allow the conceptual system to be reduced to practice.

III. Realized measurement capabilities, i.e., abilities to measure specific quantities to known accuracies under defined conditions.

IV. The institutional dissemination and enforcement network; components include NBS, state and local weights and measures agencies, standards laboratories, and some regulatory agencies.

$V$. End-use measurements, which all other levels of the system exist tn cunnort.

Supporting all of these leveTs is a central pillar of measurement science, know-how, and trained people.

Interactions among different institutional sectors of the system have been described by a direct measurements transactions matrix.

Measurements cost an estimated $6 \%$ of GNP. About $85 \%$ is for labor. All 78 major industrial sectors, all levels of government, and consumers buy measurement equipment or labor. Federal, state and local governments are the largest user sector, about $35 \%$ of the total. Other service industries, principally trade, utilities, transportation and communication, account for about 25\%. "High technology" manufacturing industries spend a larger share of their value-added but relatively few actual dollars. Preliminary correlations of measurement intensity with economic growth and productivity data for major industrial sectors reveal a significant positive correlation.

The technical microstudies reveal a number of serious deficiencies, especially in areas associated with governmental regulation for health, safety, and environmental protection. They provide information used by NBS to define new program directions.

Even in such basic areas as measurement of time, length, and mass, there are needs for improvements, for example, in mass measurements for inventory control of fissionable nuclear materials. Economics is a prime 
motivator for a number of dramatic technological changes: satellite time and frequency broadcasts, electronic distance-measuring surveying equipment, and automated digital grocery store scales. The major problems are those of scaling to large or small magnitudes, e.g., very precise navigational positioning, measuring the volume of oil in a supertanker or the breadth of a line in an integrated circuit.

On the other hand, there are deficiency areas where it is hard to say that a national measurement system even exists: Surface properties (of importance in such diverse areas as catalytic petroleum refining and microelectronics) and medical ultrasonics (used for detecting cancer and monitoring the unborn), fields which have blossomed dramatically very recently. Far ultraviolet radiometry (used in phototherapy of newborn infants and for monitoring the earth's shielding ozone layer), a field in which measurement standards have existed only recently. Spectrophotometry (of importance in all fields of color and appearance and lighting), because of a lack of national leadership until recently. Electromagnetic interference phenomena (of importance in virtually all uses of electronics), because of the subtlety and complexity of the measurement problems.

The most critically important deficiency area identified is in the measurement system needed for the safeguards program for special (fissionable) nuclear materials, and NBS has initiated a major program here in collaboration with ERDA and NRC.

Other areas in which improvements in the system are needed include the following:

1. A firm base for measurement under dynamic, time-varying conditions, of force, fluid flow, pressure, temperature, humidity, electrical quantities, and tohers.

2. Standards support to high speed, dynamic, automated measurement sys tems, in electronics and electromagnetics.

3. Measurements made under hostile environmental conditions, such as the measurement of temperature, pressure, neutron flux, and fission rates inside nuclear reactors.

4. Precision characterization of many kinds of measurement transducers, especially for temperature and pressure.

5. Non-contacting, on-line, manufacturing instrumentation for measurement of surface finish parameters.

6. Flow measurements in the field, such as low air velocities for mine ventilation, water supply and waste water flows for pollution control, metering of natural gas, and multi-component flow.

7. Measurement assurance for auto tire pressures and aircraft altimeters.
8. Electronic medical themometry.

9. Measurement of moisture in grain (in conjunction with the Dept. of Agriculture).

10. Gathering and predicting measurement data on the thermodynamics of fluids, especially complex mixtures in support of such fields as the chemical and petroleum refining industries.

11. A measurement system and data for liquified natural gas, and for superconductivity in the electrical power industry.

12. Measurement techniques for monitoring nolse to support its regulation and control.

13. Widely available $1 \%$ end-use measurements in radiometry and photometry, where $20 \%$ is common today, in support of many new areas of lighting and optical technology.

14. Improvement of measurement of ionizing radiations used in medicine, to which workers are exposed, or present in the environment.

The major trends of the System are these:

Increased complexity, resulting from the ever-increasing scope of science and technology, from the development of the information economy, and from the challenge of mastering the ever-growing complexity of our society.

Improved quality control.

Improved information resources.

Automation.

Metrication, to bring the U.S. into line with the rest of the world.

Consolidation of the scientific revolution in the basis of the system--the shift from dependence on artifacts to natural phenomena as our basic standards.

The most significant deficiency lies in the lack of adequate mechanisms for quality assurance throughout the measurement system. Closely related is the wide-spread need for more "how-to" information at the working leve1. Inversely, NBS and other infrastructural institutions need more knowledge of real needs of the system.

As the central measurements standards institution in this country, NBS contributes to every aspect of the National Measurement System. Its two primary unique functions are custody of the national standards of physical measurement and promotion of the health of the entire National Measurement System.

NBS is currently responding to most of the measurement systems needs identified by this study. Most especially, NBS is moving to meet the needs of a new major sector of the system: measurements for establishment of, enforcement of, and compliance with, governmental regulations. The major challenge facing the Bureau is that of wise deployment of our resources, as other demands are put on NBS expertise, to support the needs of a constantly expanding Nationa 1 Measurement System. 


\section{INTRODUCTION}

\subsection{Concept of a National Measurement System}

The "Concept of a National Measurement system" has been discussed by NBS authors and spokesmen for a number of years. In the 0ctober 6,1967 , issue of Science, [1], Dr. R. D. Huntoon wrote:

"Concurrently with the growth and industrialization of this nation, there has developed within it a vast, complex system of measurement which has made possible the very growth that brought the system into being. This National Measurement System stands today as one of the key elements in a world-wide measurement system that links a 11 major nations together in a consistent, compatible network for communications and trade."

"Our National Measurement System is one of a number of mutually interacting systems within our technologically based society that form the environment in which the individual citizen must live and function. Familiar examples are the communication, transportation, educational, medical and legal systems...."

"The National Measurement System, which evolved in this country with little formal recognition as a system, is now being examined... at the Nationa 1 Bureau of Standards (NBS)... partly because of the all-pervasive nature and great economic importance of the nation's measurement activities, and partly because of the challenge to NBS in putting its splendid new facilities to optimum use for the benefit of the nation. Such optimum use can be approached only when the National Measurement System, of which NBS is a central element, and the services it requires for effective operation are sufficiently well understood." [1]

Today, we define the U.S. National Measurement System as comprising all of the activities and mechanisms--intellectual and operational, technical and institutional--used by this country to produce the physical measurement data needed to create the objective, quantitative knowledge required by our society. This knowledge is used to describe, predict, communicate, control, and react, in many aspects of our personal and social lives, science and technology.

+Figures in brackets indicate the literature references at the end of this report.

\subsection{Background of Present Study}

In a memorandum dated April 12, 1972, the Assistant Secretary of Commerce for Administration directed the preparation of a study of "the NBS standards of measurement to determine if their accuracy is sufficient for the needs of U.S. industry."

In response to this request, two actions were taken. One was to prepare an immediate reply based on the evidence then available. The second was to initiate a three-year study of the National Measurement System for the purpose of developing answers in depth to the questions posed. This report is a summary of the resulting study. Currently relevant excerpts from the immediate reply [2] are quoted below:

\section{"Compatibility of measurement through stan-} dards is a fundamental aspect of a world organized for the interchange of goods and ideas, i.e., of a civilization.... The immediate origins of the modern system of standards are to be found in the late 19th century, that period when the full flowering of America as an industrial society was occurring. [3] To agrarian concerns over diversity of measures for weight, fluid volume and land area would shortly be added the need to meter electrical energy, to know the heating value of fuels and the lighting value of illuminants, and to assure the interchangeability of manufactured parts."

"The creation of a national system of measurements to which all could repair seems quite analogous to the struggles towards a uniform currency which were occurring in the same era and which culminated in the Federal Reserve Act of 1913. A rational, selfconsistent system of physical measurements is the 'currency' of science and technology."

"The physical measurement system cannot measure its own value to society... standardization is inextricable from the whole apparatus by which social life is organized, and it stands or falls with the society as a whole." [2]

The specific questions posed in the Departmental memorandum of Apri1 1972, and excerpts from the NBS answer of July 1972, are the following [2]:

"Do NBS Standards Meet the Needs of U.S. Industry?

"Whether we relate the above question to industry only or construe it more broadly, the answer is qualitatively the same: 
NBS standards do oppear to meet most needs. However, technology continually advances by means of new discoveries, and at any given time there will be new needs in certain areas that require attention."

"Since 1946, new needs have tended to appear first in the programs of government agencies using advanced technologies (e.g., defense, aerospace, and atomic energy), from where they have diffused into client industries and then to civilian industry."

"More recently, a different pattern has emerged in which the measurement needs are being generated by public concern for well-being and safety. These are finding expression in recent legislation and in the regulatory measures being promulgated by such bodies as the Environmental Protection Agency, the Department of Labor, and the Bureau of Radiological Heal th....

"However, some measurements needs do arise directly from civilian industry. Following are some current examples:

o High voltage...

o Photometry...

o Electronic thermometers..."

"In cases where the stondards should be improved, how much should they be improved, what would be the benefits of improving the standards and how much would it cost?"

"obtaining... answers is one of the main goals of the three-year study now under way."

"What role do NBS standards play in increasing U.S. industry's ability to compete in foreign markets? Are there standards, presently rnavailable or capable of improvement, that would give U.S. industry a competitive edae in foreign markets?"

"It is essential for a nation exporting advanced industrial products to use an internationally recognized and compatible system of units, to possess standards of such measurement units, and to have procedures for referring all critical measurements to those standards.... This is especially true of high-technology products, which today are the healthiest sector of U.S. export trade."

"Are there predictable technological developments that would create a need for NBS stantards not now available?"
The answer to either of two possible versions of this question in "Yes:"

"Are there predictable developments=in measurement technology of such importance to the improvement of measurements that NBS could not responsibly neglect them?"

"Can we identify beneficial future technologies that cannot be brought to full fruition unless appropriate new kinds of standards are provided by NBS?"

"What is the NBS plan for improving and refining the accuracy of standards in the future?"

"We feel it is important to discuss this question much more broadly, i.e., in terms of meeting needs, not just in terms of 'improving accuracy." "

"We have set in motion an extensive planning exercise to be vigorously pursued during FY 73-75 by all units of IBS. It employs many of the techniques and inputs used in the past. This long-range planning study amounts to a detailed analysis of what we have often referred to as the National Measurement System [4]. This is being accomplished simply by bringing a much larger NBS workforce to bear on the problem and by developing and drawing on a much more extensive body of outside contacts." [2]

The 1972-75 IBS Study of the National Measurement System was initiated in 1972 by Dr. Ernest Ambler [5]. The stated aim was to undertake a drastic speedup in the extent and depth of Institute program justification efforts so as to accomplish an across-theboard analysis of the entire scope of Institute measurement and dissemination concerns. The approach to the study involved analys is of the totality of the physical measurements performed in this country to answer the question of the quality of the measurements being made by the system and whether NBS dissemination procedures are adequate for $i$ ts needs. The motivation for the activity was to:

"1. Provide management with enough information to allocate limited resources to most timely, significant programs.

2. Assist in obtaining our resources by demonstrating clear concept of responsibilities... demonstrating that we have evaluated the needs, considered the alternatives; employed good management practices.

3. Motivate our own people to improve the management of public funds spent on technological progroms." [6] 


\section{IMPLEMENTATION OF STUDY}

\section{1 Organization of Study}

A. A series of "microstudies" of specific aspects of the system was initiated, defined on the basis of the technical measurement fields with which the Institute deals. Thus, the total system was examined with respect to a series of different, specific kinds of measurements.

Implementation of the microstudies was delegated by the division chiefs to "study representatives." Typically these study representatives were chiefs of the sections responsible for the kinds of measurement being studied. These study representatives often enlisted support from many others in their divisions, so that the total number of study contributors and report authors was quite large.

The final roster of microstudies and of

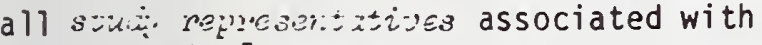
them is this [numbers in brackets reference the key reports generated]:

Time and Frequency - Allan S. Risley (Time and Frequency Division) [ 7]

Length and Related Dimensional Measurements John W. Lazar (Mechanics Division) [8]

Vibration and Shock - John D. Ramboz (Mechanics Division) [ 9 ]

Surface Finish - Russell D. Young (Mechanics Division) [10]

Mass, Volume and Density - James R. Whetstone, James A. Simpson, B. Nelson Norden (Mechanics Division) [11]

Force - Donald E. Marlowe (Mechanics Div.)[12]

Fluid Flow - William C. Haight, Philip R. Compton (Mechanics Division) [13]

Pressure - Peter L.M. Heydemann (Heat Div.) [14] Temperature - James F. Schooley (Heat Div.) [ 15] Humidity and Moisture - Arnold Wexler (Heat Division) [16]

Thermodynamic Properties of Fluids - Max Klein (Heat Division) [17]

Cryogenics - Thomas M. Flynn (Cryogenics Division) [18]

Electricity - Norman B. Belecki (Electricity Division) [19]

Electromagnetics - Robert A. Kamper, Francis $X$. Ries, Wilbur J. Anson (Electromagnetics Division) $[20,21]$

Medical Ultrasonics - Paul A. Hudson (Electromagnetics Division) [22]

Acoustics - David S. Pallett (Institute office) [23]

Radiometry and Photometry - Henry J. Kostkowski, Bruce W. Steiner (Optical Physics Div.)[24]

Spectrophotometry - William H. Venable, Jr., (Optical Physics Division) [25]
Far Ultraviolet Radiometry - William R. Ott (Optical Physics Division) [26]

Optics - Dennis A. Swyt (Mechanics Div.) [27]

Lasers - Robert J. Mahler (Time and Frequency)

(note that the final report on the laser study has been integrated into that for the electromagnetics study) $[21,28]$

Physical Properties of Atoms and Molecules Arthur V. Phelps (Laboratory Astrophysics Division), John W. Cooper (Optical Physics Division) [29]

Surface Properties - Cedric J. Powell (Optical Physics Division) [30]

Ionizing Radiation - Randall S. Caswell (Center for Radiation Research) [31]

B. A central coordinator for all of the studies was appointed soon after they began, $\mathrm{Dr}$. James $\mathrm{R}$. Seed, a Presidential Interchange Executive from Dow Chemical Company, on temporary assignment to the National Bureau of Standards. Dr. Seed returned to Dow Chemical Co. in early 1974. Dr. Raymond C. Sangster of NBS (the present writer) took up the coordination responsibilities in August 1974.

\section{A macroeconomic study was undertaken} of the cost dimensions of measurement-related activities in our economy. Dr. Paul U. Pawlik, working under the guidance of Dr. Howard E. Morgan, an NBS staff economist, conducted a study to define the gross "value-added" economic dimensions of the national measurement system. [32,33] Later, Dr. Morgan extended the macroeconomic study to include analys is of capital investment and current expenditures for measurement instrumentation. [34]

D. During final phases of the study, support was enlisted of Charles $W$. Howe, Bernard Udis, and Barry W. Poulson of the University of Colorado, Department of Economics; and of Charles T. Stewart, Mary A. Holman, James R. Barth, and James $T$. Bennett, of the Department of Economics of George Washington University. The objectives of this support were to provide critiques and guidance directly to the authors of the microstudies, to strengthen the economic aspects of their reports. During the course of their involvement with the microstudy authors, this group of economists developed additional insight into the macroeconomic aspects of the national measurement system, and Prof. Poulson was retained to write a summary report on the economic aspects of the total 1972-75 study [35]. 


\subsection{Approaches to Study}

There was an obvious effort made to graft the new national measurement system microstudies onto ongoing efforts of a similar nature. As a matter of deliberate management policy, few formal procedural requirements were imposed on the separate microstudies during their first 18 months. As a result, initial interim reports generated in December 1973 exhibited a substantial variety in their approaches to the studies. During this first 18 months or so, coordination was effected by the analysis of two annual plans and of one substantial written report for the mi crostudies; by personal counseling between the central coordinator and the study representatives; by a major workshop in which all participants described their approaches and results to date; and by discussion at semiannual major division chiefs' meetings.

The current phase under Dr. Sangster began with personal conferences with the division chiefs and their study representatives. The interim reports were used as a data base for an inductive development of a master model of the national measurement system. This model was then used to develop a draft outline for the final measurement system study reports, and to evaluate the existing reports. Another workshop was held to communicate these results and to reach a meeting of the minds about the nature of what needed to be done to complete the study.

The central coordinator has also had a responsibility of interacting with the rest of the measurement system, to represent the measurement system study as a whole, both by personal contact and by study and analysis of the literature.

\subsection{Techniques for Observing the System}

The techniques for observing the system are of primary importance in the methodology of the study. They can be described in terms of:

(1) the selection mechanisms that are used to determine the sources of information or validation;

(2) the contact mechanisms and transmission media used to obtain the actual data; and

(3) the specific sources of data that are actually used.

The actual mechanisms and sources used are displayed in table 1, in an approximate order or importance, averaged over the total study.
Table 1. Techniques used for observing the National Measurement System (in approximate order of importance).

Mechanisms for selection of sources

Staff judgment or wisdom

Analyses of NBS clientele

Analyses of instrumentation industry

Analyses of membership of National Conference of Standards Laboratories

Analyses based on Standard Industrial

Classification codes

Other (statistical reports, etc.)

\section{Sources of information or validation for study}

Private companies, directly

Instrumentation industry

Staff wisdom \& publications; previous studies

Federal government agencies, nonregulatory

Professional \& technical socjeties \& publishers

Documentary standards bodies; laws

NBS evaluation panels

Academia - people \& organizations

Trade associations

other NBS units

Federal regulatory agencies

Standards \& testing laboratories \& services

Trade press, including advertisements

International \& foreign organizations

National Conference of Standards Labs.

State \& local government agencies

State \& local Offices of Weights \& Measures; Nat'l Conf. W \& M

Reference data \& materials organizations

Popular press, including ads

Consumer organizations

Contact mechanisms \& transmission media

Literature search (all varieties)

Telephone

Visits to sources" sites

Correspondence

Conferences \& meetings, general

Visitors \& trainees at NBS

Special conferences, etc.,

NBS sponsored

Round robins, intercomparisons

Formal polling, canvass, questionnaire

Exhibits by NBS - trade shows, etc.

Consultants

Delphi or other special technological forecasting techriques. 


\section{FINDINGS OF STUDY}

This section summarizes the major findings of the 1972-75 IBS Study of the National Measurement Sys tem.

\subsection{Model of the System}

The model of the National Measurement System developed by induction from interim microstudy reports prepared in December 1973 and from previous literature on this subject $[1,4,36-48]$ can be considered to have five major levels:

1. The inteilectual foundation is the conceptual system that defines the measurement quantities and units. The measurement system of the United States is founded upon one basic conceptual system of phenomena, quantities, and properties (established by international agreement), and upon two systems of units, the "Customary" system based on old English measurement units, and the modernized metric system, the Systéme International (abbreviated SI) $[37,38,49-69]$.

11. The basic technical infrastructure provides the tools and techniques and agreements that allow the conceptual system to be reduced to practice. The technical infrastructure elements have been defined to encompass:

1. A documentary specification system [70-76].

2. An instrumentation system of physical standards, techniques, and instruments, supported by an instrumentation industry $[34,77-80]$.

3. A reference data system [81-84].

4. A reference materials system $[47,85-91]$.

5. A central core of supporting knowledge and science.

III. Realized measurement capabilities the ability to measure specified quantities to known precisions and accuracies under defined circumstances - form the heart of the measurement system. The whole system centers on this level. The lower levels are meaningful only as they result in realized measurement capabilities. The higher levels can achieve no more than these capabilities a 11 ow. (See table 2.) $[38,50,57,60,77,92-105]$.

IV. The dissemination and enforcement network exists to make the realized measurement capabilities available to the ultimate users and to enforce the adequacy of their use where this is called for by law or accepted practice. This network provides the institutionai infrastructure of the sys- tem. Since one function of the national measurement system is to allow compatibility in international commerce, both national and international institutions are relevant. The general kinds of institutions involved can be described as the central standards authorities responsible for physical measurements, the state and local offices of weights and measures, standards and testing laboratories and services, and those regulatory agencies that must specify measurable physical requirements in the field that they are regulating [36].

As the central measurement standards authority in the U.S., the National Bureau of Standards is broadly responsible for monitoring and supporting the health of the entire measurement system $[3,39,44,55,80$, 104,106-116]. Other institutions in this country have only secondary central measurements standards roles; the most important of these is the provision of astronomical time of day by the U.S. Naval Observatory [7]. Our ultimate central standards authority is a supranational organization, the International Bureau of Weights and Measures $[54,61,63,68]$.

Legal responsibility for enforcement of justice in use of weights and measures in our domestic commercial marketplaces lies with state and local offices of weights and measures. The National Conference of Weights and Heasures is the central coordinating body for operating agencies in this field. Its paid staff and executive secretariat are provided by the NBS Office of Weights and Measures $[3,55,58,77,117-130]$.

Stanjards and testing laboratorles and services function as "miniature NBS's" to provide physical standardization services to specific portions of the National Measurement System. The National Conference of Standards Laboratories (NCSL) is the central organization in the field. NBS provides the central secretariat for this organization $[10,92,105,131-136]$.

Wi th the development of modern technology and the increase in the complexity of society, more and more regulatory roles have been assumed by the formal governmental structure. Table 3 indicates some of the Federal regulatory agencies, both within the Executive Departments and located independently. Actions of the regulatory agencies have a major impact on the measurement system, since promulgation of optimal regulations requires a measurement capability that allows the necessary data to be obtained and sound decisions to be made in such areas as 
Table 2. Realized measurement accuracies

\section{Measurement Quantity}

Time and frequency:

NBS -5

Commercial Cs beam devices

Length:

$\mathrm{Kr}-86 \mathrm{lamp}$, NBS

NBS end-std. calib.: $25 \mathrm{~cm}$

Geodetic surveying

Surface Finish:

Mass:

International comparisons

Class M laboratory weights

Commercial test weights

Volume: Laboratory use

Density: NBS

Force:

NBS deadweight standards, corrected for air buoyancy Working calibration standards

Vibration: NBS

Fluid Flow:

Air flow, NBS

Pipelines, liquid and gas

Water, open conduits

Pressure:

NBS standards

Military maintenance stds.

Temperature:

Water triple point

Commonly used sensors

Humidity:

NBS

Commercial humidity meters

Moisture: In grain

Thermodynamic properties of fluids:

$\times 10^{-6}$

$1 \times 10^{-5}$

to $5 \times 10^{-4}$

$$
\begin{array}{r}
2-3 \times 10^{-9} \\
5 \times 10^{-6} \\
1 \times 10^{-4} \\
5 \times 10^{-4} \\
5 \times 10^{-6}
\end{array}
$$

$2 \times 10^{-5}$

$1 \times 10^{-5}$
$5 \times 10^{-5}$

$1 \times 10^{-2}$

$1.5 \times 10^{-3}$

$1-3 \times 10^{-2}$

$$
3-6 \times 10^{-5}
$$

$1 \times 10^{-4}$

$1 \times 10^{-3}$

up to $2 \times 10^{-1}$

to $\begin{aligned} & 1 \times 10^{-4} \\ & 5 \times 10^{-3}\end{aligned}$

cryogenics:

Pressure transducers-

$\begin{array}{lr}\text { commercial } & 5-10 \times 10^{-2} \\ \text { Temperature-commercial } & 10^{-4} \text { to } 10^{-2} \\ \text { Flow--NBS research facility } & 1 \times 10^{-3}\end{array}$
Frequencies, NBS

Power and energy. NBS

Mea surement Quantity

Electricity

OC voltage, NBS

RMS voltage, $10 \mathrm{kHz}$, NBS

Capacitance, NBS

Resistance, NBS

Electromagnetics

Impedance

Attenuation

Phase delay

Power

Vol tage

Noise

Field Strength

Es timated

(Parts per unit)

Medical Ultrasonics: power

$1 \times 10^{-7}$

$2 \times 10^{-5}$

$1 \times 10^{-7}$

$8 \times 10^{-8}$

Acoustics:

Sound pressure, NBS

Noise exposure, commercial

$1 \times 10^{-3}$

to $2 \times 10^{-1}$

$5-10 \times 10^{-3}$

$1-10 \times 10^{-2}$

$10^{-4}$ to $2 \times 10^{-1}$

$5-300 \times 10^{-2}$

$3-20 \times 10^{-2}$

$5 \times 10^{-2}$

Radiometry and photometry:

NBS

Field workers

$1-5 \times 10^{-2}$

$5-10 \times 10^{-2}$

Spec trophotometry:

Transmittance, NBS

Reflectance, NBS

$3 \times 10^{-4}$
$5 \times 10^{-3}$

Far ultraviolet rajiometry:

Detectors, NBS

Sources, NBS

$6-10 \times 10^{-2}$
$5-10 \times 10^{-2}$

Optics:

Resolution limits

Optical density

Lens diopters, NBS

1000 lines per mm

$5 \times 10^{-3}$
$10^{-4}$

Physical properties of atoms and molecules:

Energy levels

Atomic hyperfine separation

Cross sections, electrons

Cross sections, atoms/ions

Oscillator strengths

Electron drift velocity

$$
10^{-10} \text { to } 10^{-9}
$$

$5 \times 10^{-12}$

to $1 \times 10^{-6}$

$1 \times 10^{-13}$

$3-20 \times 10^{-2}$

$1-2 \times 10^{-1}$

$1-5 \times 10^{-2}$

$5 \times 10^{-3}$

Surface composition: $0.1 \%$ of an atomic layer 0.1 um lateral resolution

Ionizing radiation: NBS $\quad 1.5 \times 10^{-2}$ 
Table 3. Examples of Federal regulatory agencies

Civil Aeronautics Board

Consumer Product Safety Commission

Environmental Protection Agency

Federal Communications Commission

Federal Power Commission

Federal Trade Commission

Food and Drug Administration

Interstate Commerce Commission

Mining Enforcement and Safety Administration

National Highway Traffic Safety Admin.

Nuclear Regulatory Commission

Occupational Safety and Health Admin.

the feasibility of enforcement; erforcement by the regulator requires comparison of actual conditions with the prescription of the regulations, and this often means measurements; com liance by the regulatee similarly requires an ability to measure; and adjudisation requires measurements that will stand up in court.

V. The ultimate level in the system consists of the end-use measurements made and used in the "Measurements market-place". It is this level that all other elements in the system exist to support. The technique that has been chosen for displaying these and other measurement activities is a measurement transactions matrix, which displays the direct interactions among the various suppliers and users of measurement information, data, goods, and services [137].

\subsection{Status of the System}

While the U.S. national measurement system is overall in reasonably good health, there are both systematic and specific deficiencies that can and should be corrected. There are several specific areas (detailed below) in which the measurement system will be subjected to severe strains in the foreseeable future, unless appropriately responsive steps are taken during the next several years.

The strengths of the U.S. National Measurement System are many. For example, the U.S. instrumentation industry is strong-exports exceed imports by a factor of two, at the billion dollar level [78]. The country has a strong measurement institutional infrastructure: NBS, the state and local weights and measures agencies, the industrial and governmental standards laboratories.
The most fundamental structural deficiency in the system lies in its frequent lack of adequate stabilizing "feedback" mechanisms. simply, there are not enough provisions in the system to assure that the measurement data needed are actually provided with the necessary quality, at minimum cost, or to assure that information about measurements is available to the people who need it.

The main systematic technological deficiency in the system lies in the lack of support by NBS of a wide variety of practical measurements: Measurements of quantities under dynamic conditions, where the measurement variable is changing during the measurement process. Measurements under a variety of environmental extremes: temperature, pressure, humidity, etc. Measurements made by convenient but poorly characterized transducers. System needs in this general area have been recognized during many of the microstudies, and a number of program activities have been initiated toward satisfying them.

The primary institutional deficiency in the system is in the area of measurements in support of technological regulations, where neither the regulatory agencies nor those being regulated have an adequate institutional focus on their measurement problems.

\subsection{Trends of the System}

Continuing NBS activities in long standing program areas such as static force and analog electrical measurements assure that these portions of the measurement system are adequately supported. The emerging technologies typically have problems. There are rapidly rising measurement demands associated with the recent dramatic expansion of governmental regulatory activities in the fields of environmental protection, occupational safety and health, consumer protection, and radiation safety.

The major trends of the national measurement system can be described under the following headings:

\subsubsection{Increased Complexity}

Increased complexity is the result of three major driving forces: (a) advancements in science and technology, (b) the development of the information economy [138], and (c) the challenge of mastering the evergrowing complexity of our society as a whole. 
The growth of the information economy increases pressures on the National Measurement System. Data created by physical measurements comprise one major source of input information. An apparent "saturation" of the economy by information activities [138] increases the importance of an ability of the measurement system to deliver exactly the data needed, when it is needed, with exactly the required quality.

The issue of managing the ever-growing complexity of our society is probably the greatest single driving force that the measurement system faces today $[139,140]$. Our society can no longer afford the complexity introduced by poor, inadequate, or excessive measurements. The measurement system provides the foundation of data about the physical universe that allows the industrial system and society to function. Confusion about these data introduces confusion and complexity at the most fundamental level. The social driving force for reduction of social complexity means that confusion in the physical measurements data base will become increasingly intolerable. We must have the data we need, and we must know that it has the reliability that we need, no more and no less. We will increasingly be unable to afford to guess about the validity and adequacy of our fundamental data.

Specific examples of the need for quality control of measurement data occur in such areas as the enforcement of pollution control regulations. The Environmental Protection Agency is acutely concerned about this problem. Development and application of methods of ensuring that the recorded data base is meaningful is expensive and complex, but without these methods gross mistakes can be made. A few years ago several monitoring stations on a major lake reported about a twenty percent jump in the level of a pollutant. The obvious action decision was to seek out the pollutors who had gone out of control. In fact, inquiry to the monitoring stations revealed that they had just put a new and more accurate measurement method into service. But ten years from now, will anyone examining the recorded data base know this? And will they jump to the wrong conclusions regarding the historical pattern of pollution in this lake? (For example, "despite all the efforts..., in 197 a major pollution surge occurred; obviously, the control efforts had been futile!").

Because of such problems, EPA factors into its assessment of any pollution data reported to it an intuitive adjustment factor for the reliability of its source, which may range from awful to quite good. And whenever any enforcement actions are anticipated, a team goes in to make under very carefully validated conditions any measurements that are needed to provide data that may need to be used in court. The routine monitoring data simply aren't reliable enough. +

\subsubsection{Increased Integraton of the System}

Increased integration of the measurement system is essential to provide most economically and effectively the measurement data required by our society. Two primary opportunities exist for such integration. One is in the substantial expansion of the significance of measurements for Federal government operations, which suggests that a coordinated integrated approach could yield substantial dividends in operating efficiency. The second is at the state level where a vast expansion of regulatory measurement responsibility is taking place. Looking at the total needs within a state at the state and local levels, and at all available resources, can lead to a state measurement system network that gets the job done at far less cost than would occur if every new need were met by developing a new measurement capability specifically to meet it.

\subsubsection{Improved Quality Control in the System}

With one major exception, the historical orientation of the institutional infrastructure of the national measurement system has been passive, that of making it possible for people to make the good measurements that they need. It has been assumed that the people making the end-use measurements would achieve whatever measurement quality they needed, if they were simply provided an inherent capability to make the needed measurements. Providing systematic quality assurance mechanisms has been largely neglected. The one major exception to this rule has been in the commercial weights and measures field, where there is adequate historical evidence that inaccuracies tend to favor the sellers [3], and society has since Biblical times reacted to enforce minimum quality standards for weighing and measuring operations in commercial transactions.

As a general rule, where significant quality control feed-back loops exist in the $\mathrm{Na}$ tional Measurement System, the system is functioning adequately. Where they do not exist, it is not functioning adequately. Examples of quality control loops that do work are the following:

tReport by Denver EPA representatives at meeting of Colorado section of the Precision Measurements Association, Jan. 25, 1977. 
(1) In weights and measures enforcement. In addition to classical enforcement methods of certifying equipment and spot checking the product, newer techniques are in use:

(a) Cooperation with the original packager (manufacturer) to assure adequate and legally certified measurement quality can eliminate the need for inspection of his products in a multitude of localities.

(b) Some states are developing an approach to shift the responsibility for assuring accurate weights from the weights and measures agency to the weigher. A program that helps the weigher to achieve good weights and that rewards him for it (among other things, by a reduced frequency of inspections) is inherently a positive approach to optimizing the workings of the measurement system [121].

(2) In technological measurements. Neither the manufacturer nor the buyer really cares about the exact measurement values achieved in the dimensions and surface finish of a cylinder of an automobile engine, for instance. But they do care that the engine works. Inadequate measurements will lead to engines that don't work properly and to parts that will not fit, a problem made more acute by the fact that a given manufacturer may rely on many other manufacturers for parts that will fit together properly in the final product. There are inherent feedback mechanisms here that drive the measurement system toward producing the quality of measurements needed. External policing is not needed.

(3) The NBS-sponsored Measurement Assurance Programs.

Over the past decade or so, the concept of measurement assurance has grown up within the community revolving around the National Bureau of Standards, the National Conference of Standards Laboratories, and the National Conference on Weights and Measures. The objective is to provide key elements of the national measurement system not only a capability of making good measurements, but also tools that would provide quality assurance information so that they would know in fact whether or not they were making measurements of adequate quality. These programs calibrate all aspects of a client's specific measurement operation. Succinctly, the client is provided measurement objects which he proceeds to handle with his own instruments and personnel. The measurement data generated are analyzed by NBS and the client is told how well his measurement system is operating [141].

\subsubsection{Improved Information Resources for the System}

Other major stabilizing feedback loops that are often inadequate are in the area of the flow of measurement information:

(a) The people making measurement frequently do not have adequate information accessible to them. They often are unaware of the capabilities of the National Bureau of Standards or other central agencies, and are not aware of the assistance that they can get. The "how-to" knowledge that they need is often hard to find.

(b) The people in NBS and other central institutions are often only partly aware of the real needs of the people making end-use measurements. They may not know how they can, in fact, provide the optimum assistance to the end-use parts of the system.

This study is, of course, a specific step to improve the situation in this knowledgeflow area, especially from the system to NBS. Furthermore, the most consistently overwhelming action conclusion reached by the various microstudies is of the need for more publications by NBS of the "how-to" variety, to get the needed information out into the hands of the users. NBS is responding, through such means as metrology guides and self-study manuals [142-144].

\subsubsection{Automation of Measurements}

The application of automatic data taking and processing techniques is having as revolutionary an impact on the field of measurements as the applications in many other areas of our culture. The machine is augmenting both man's brain power and his hands in the field of measurements. Today, the machine can control the measurement process, sense the raw data, compute meaningful data output, and feed the results back into the control function to optimize the ultimate product. The computer is allowing both new kinds of measurement and new approaches to measurement, which were previously impractical or impossible.

\subsubsection{Metrication}

With the passage of the Metric Conversion Act of 1975 a major trend in the system is clearly confirmed: The customary U.S. set of measurement units will be substantially supplanted by the metric, SI units. This conversion to the metric system will have significant measurement system impacts in 
the areas of education, publicity, industrial standards, and instrumentation modification, and will provide an opportunity for a genera? "housecleaning" of the system as the metric changeover occurs - a reduction in the number of standard sizes, elimination of obsolete equipment, and the like [145].

\subsubsection{Science}

The measurement system is in a scientific revolution, which is replacing mechanical artifacts as reference standards with atomic wavelengths and similar invariant natural phenomena, and which is providing a similar revolutionary basis of measurement technology $[37,38,50,57,59,64,146,147]$.

\subsection{Economic Analysis of the National Measurement Sys tem}

A macroeconomic study was conducted of the cost of labor and equipment used for making measurements in each of 78 major industry groups $[33,34]$. The Department of Labor made available staffing schedules and job analysis sheets, for 1967-72. Estimates of the proportion of labor time devoted to physical measurements were based on the job analysis sheets, and staffing schedules allowed extrapolation to estimate labor costs for major industrial groups. Information on expenditures for selected classes of measurement devices was obtained from the 1963 Input-Output model of the U.S. economy, the latest data available at the time this study was done. Table 4 summarizes some of the results of this study.

The making of physical measurements was found to be ubiquitous in the economy. All sectors incurred substantial expenditures for measurement equipment and labor.

Measurement cost an estimated $6 \%$ of gross national product (GNP), or $\$ 36$ billion, in 1963. About $85 \%$ of this was for labor.

Mechanical and controlling instruments ranked highest in the value of instrumentation output in 1963, at $\$ 1.3$ billion. Most of these devices measure derived units of length, mass, or heat. The motor vehicle manufacturing industry was the largest buyer, followed by aircraft manufacturers and electric/gas/water utilities. Electrical measuring and test equipment ranked second at \$939 million; major customers were government, electric utilities, the telephone industry, and radio/TV/communications equipment manufacturing. Engineering and scientific instruments, and industrial controls, ranked third and fourth.

Measurement intensity data have been compared [35] against industrial output and productivity data $[148,149]$. Table 5 indicates a summary comparison. The results are in accordance with expectations, namely, that greater measurement intensity should be associated with newly developed products and growth in industrial output, and new production processes and increases in productivity.

Table 4. Measurement intensity of principal using industries, 1963

(ranked by amount and percent of value added by measurements)

Industries Ranked by Dollar

Amount of Value Added
Industries Ranked by Percent of Value Added
Industry

Value Added

Government

Trade

New Construction

Ele., Gas \& Water Util.

Aircraft Mfg.

Transport \& Warehsg.

Radio, TV \& Commun. Eqpt.

Finance \& Insurance

Telephone \& Telegraph

Primary Iron \& Steel

$\$ 11,342 \mathrm{M}$
4,256
1,348
1,149
1,106
981
970
817
809
802

\section{Industry}

Percent

$\underline{\text { Rank }}$

1

2

3

4

5

6

7

8

9

10
Radio \& TV Broadcasting

Government

Aircraft Mfg.

Electronic Comp

Office Equipment \& Computers

Radio, TV \& Commun. Eqpt.

Plastics

Chemicals

Elec. Trans. \& Dist. Mfg.

Textiles \& Floor Cover
27.0

20.6

16.8

16.5

16.4

16.3

12.2

11.4

10.6

10.3

Table 5. Economic growth of measurement-intensive industries

Measurement-intensive industries

Increase in Output

$\frac{1960-66}{11.6 \%} \quad \frac{1964-70}{5.3 \%}$

$8.4 \%$
$4.9 \%$
Increase in Productivity

$\begin{array}{cc}\frac{1960-66}{5.5 \%} & \frac{1964-70}{2.7 \%} \\ 4.2 \% & 2.4 \%\end{array}$


The Metric Study is the only other substantial source of macroeconomic data on the quantitative dimensions of the National Measurement Sys tem [150]. This Study examined the effects on the United States of increased world-wide use of and conversion by the U.S. to the metric system. Estimates of costs of metrication are subject to a wide range of error, and the evidence is that they are biased lipwards [151]. However, a net impression remains that the macroeconomic dimensions of the measurement system suggested by the Metric Study are remarkably consistent with those derived by Morgan and Pawlik $[33,34]$. For example, government's share of the costs of metrication is estimated at $36 \%$; its share of total estimated measurement cost is $35 \%$.

The overall economic study [35] has emphasized that measurement is part of the knowledge or information sector. This is an area where economic analysis is in its infancy. As additional theoretical and empirical work becomes available, relating to the production of knowledge, it is important to examine the relation of measurement information to the information sector as a whole.

The analysis of the costs and benefits of measurement in the private sector reveals a basic weakness in the methodology of the microstudies. Their perspective is that of the physical scientist and the specific measurement function he is concerned with, i.e., length, mass, time, etc. An alternative approach would be to focus on the user of measurement. To understand measurement in production one might choose a particular firm or industry and attempt to understand measurement problems from that perspective. For example, by focusing on the machine tool industry, one would find measurement problems that cut across many of the microstudies. In particular, the analysis of measurement from the standpoint of consumers has been left almost untouched in the microstudies. The perspective of producers or consumers would make it easier to explore secondary impacts of costs and benefits or measurement for the society as a whole.

\subsection{Assessments by Microstudies of Major System Trends and Needs; Programmatic Impacts of the Study}

\subsubsection{Time and Frequency [7]}

A. Three changes in the measurement system can now be predicted:
(1) One or more networks of clocks maintained in synchronism to within 1-10 $\mu$ s will be developed in the private sector or by the FAA in support of the telephone indus try, electrical power industry and aircraft collision avoidance systems. The proposed NBS satellite time broadcast service would provide adequate support for almost all such systems.

(2) There will be a significant increase in the market for frequency equalization at levels of $1 \times 10^{-8}$ and better. Users will include the telephone industry, standards laboratories, some versions of collision avoidance systems, the TV broadcast industry (if more stringent frequency control requirements are imposed by the FCC, which appears likely), and the military's Global Positioning System. The NBS TV "color burst" system is technically suited to meet such needs for all but the last area.

(3) A public demand for a more widespread watch time calibration service accurate to about $0.1 \mathrm{~s}$ is likely to materialize, since the newer quartz watches have digital displays with the seconds indication always syncronized with the minutes. No substantial technical innovations are needed, simply provision to the public at large of time signals of a quality now readily available.

\section{B. Substantially this total program is} based on the results of the National Measurement System Study and its predecessors. The current microstudy shows clearly the areas that need to be monitored in future studies.

Noteworthy in the new directions already taken have been the increased broadcast schedule for radio station WWVB, and efforts to reduce the operating expenses at WWV/ WWVH/WWVB. In the first instance, it was found that many users (especially electric power companies and seismologists) need the WWVB signals in a reliable and uninterrupted fashion, and as a result, equipment at WWVB was provided to avoid the former routine, off-the-air maintenance period. In the second instance, plans to reduce costs at the stations are being undertaken which involve a survey of the users, initiated as a part of the National Measurement System Study. This survey has revealed features of our services which are not longer needed and are being discontinued with a net cost saving.

The satellite broadcast service, when implemented, will be doubly important; it will significantly reduce the cost burden for an essential service, and also provide a time synchronization service highly compatible with the first area of probable change mentioned in (1) above. 
A new technique for evaluating certain systematic errors in beam-type frequency standards has been developed. It appears that, using this technique, commercial cesium standards can--in effect--be made accurate to better than $1 \times 10^{-12}$. This technique should be further evaluated.

\subsubsection{Length and Related Dimensional Measurements [8]}

A. The system is under control, in a state of dynamic equilibrium. No major deficiencies exist, and many improvements are being made as new technologies are applied to let "old" measurements be made with more precision, more accurately, more rapidly, more inexpensively, and in more detail. The most demanding NBS thrust in this area in recent years has been in the field of simultaneous multi-dimensional linear measurements, such as those associated with complex laser-controlled machine tools and with the production of very intricate, finely detailed masks for integrated circuit manufacture.

B. The first exhibit ever by NBS at the International Machine Tool Show occurred in September 1974 in Chicago. Some 4000 industry representatives visited the booth, 460 of which requested over 1300 specific technical papers, bringing NBS closer than ever before to the people in a major part of the National Measurement System.

NBS calibration procedures written at the technician level provide the type of document most useful to the metrology community that we serve. A list of available papers will be published in various trade magazines with information on how and where to obtain them.

Plans for the immediate future call for adapting more of our standard calibrations to our three-dimensional measurement facility. A short range (0-4 in.) gage block comparator was recently designed and at present is under evaluation. Another, a long range (4-24 in.) comparator is currently being completed.

\subsubsection{Vibration and Shock [9]}

The most serious problem in measurement of vibration and shock is the general lack of applicable knowledge as to how to select the proper instrumentation, install it adequately, and interpret the results correctly. Certain measurement parameters, such as mechanical impedance and dynamic force, lack standards and the measurement technology to allow them to be fully utilized. Complete and adequate specifications and general knowledge regarding vibration isolators is lacking. Vibration testing of home appliance and automobiles needs to be approached as seriously as has been testing of military equipment in the past.

The microstudy has identified a number of areas of growing civilian interest in a field long dominated by military and space applications, and a corresponding redirection of the NBS efforts has occurred. Significant work remains to be done to refine the shock calibration service.

\subsubsection{Surface Finish [10]}

A. Four measurement needs in surface finish have been identified: 1) A broad industrial educational program on new parameters for characterizing the topography of surfaces, 2) U.S. studies on the relationship between the surface finish of a part and its function, 3) the need for noncontacting, on-line instruments for measuring component finish during manufacture and, 4) the need for improved calibration and measurements in the tenth micrometer range. The U.S. has fallen far behind other countries in the characterization of surfaces. NBS must work hard to transfer its recently gained expertise in characterization to appropriate industries.

Needs are developing in some newer fields of high technology, such as microelectronics, for the measurement of single atom steps, and NBS is developing instrumentation for this purpose. A number of on-line instruments are under commercial development in this country to meet the developing needs in automation of the production line.

B. NBS joined the industry trade group CIRP (International Institute for Production Engineering Research), and is reshaping its program with new inputs. NBS priorities have been redefined to give characterization of surfaces priority second only to maintenance of existing calibration services. The third priority will go to development of certain advanced instrumentation. When requested, customer calibration reports now provide surface roughness characterizing parameters in addition to the usual arithmetric average roughness value.

Proposed new NBS programs and some recommended actions are the following:

a) Calibration of surface finish instrumentation with precision reference specimens: Continue to encourage industry to make improved precision reference specimens by upgrading our ability to measure and characterize them. 
b) Definition and testing of surface characterization parameters.

c) Improvement of resolution of surface instrumentation.

d) Development of scratch and dig standards of optical surfaces. These standards are under revision by an ASTM committee and may be sufficiently well defined in the new standard that NBS should consider providing a calibration service.

\subsubsection{Mass, Volume, and Density [11]}

A. The measurement system for mass, volume, and density is the most stable and most "adequate to the needs" of those for any of the major measurement quantities. Only a few gaps require attention. The difficulties uncovered are for the most part at the very highest levels of the system and are of importance to only a minute fraction of the physical science comunity. Adequately supported work is now in hand to straighten them out.

At the parts per million level, there is evidence that the mass scale of commerce may be offset from the theoretical unit.

Water, for various reasons, including variations in isotopic composition, presents difficulties for use as an absolute density standard. The International Union of Pure and Applied Physics has taken the lead to clear up these difficulties. It is the position of NBS that these problems are best met by development of a scale based on single crystal silicon density artifacts.

There are powerful economic-politicalsocial forces at work such as U.S. participation in the International Organization for Legal Metrology (OIML) which drive toward a more tightly governmentally controlled measurement system which would result in new responsibilities for NBS which it may, or may not, be able to meet within its present bounds of organization, funding, and staff. In the absence of major change imposed on the structure by these forces, the program level at NBS is sufficient, but further decreases in staff size, as over the last few years, would be unwise.

At the practical level, the problem of mass measurements for inventory control of fissionable nuclear materials is the most urgent one uncovered during this study.

\subsubsection{Force [12]}

A. A round robin calibration of static force transfer standards which will eventually include 30 government and corporate metrology laboratories is being conducted. Preliminary results show that the use of transfer standards may introduce excessive errors even at the first levels of their use. It is feared that further degradation in measurement accuracy will occur at each level in the eystem. The pilot study is substantially complete with the more extensive program extending into fiscal year 1977.

8. The system of standards and measurement techniques for dynamic force is substantially nonexistent. Uncertainties due to the rapid application of forces have large economic and safety ramifications where they affect such diverse fields as the metal-forming industry; in-motion weighing operations; impact testing for automotive vehicle and tire safety; testing of skidresistance of highway pavement; weapons testing; and testing of the safety, reliability, and efficiency of load-carrying systems. Extension of NBS work in dynamic force measurement and standards is planned.

C. The measurement of very small static and dynamic forces has also been identified as an area in which measurement techniques are inadequate. Such measurements are important to fields such as biomechanics, acoustic measurements, and mechanical properties of thin fibers.

D. Torque has been identified as an element of the Force Measuring System that is served only indirectly by NBS. The actual dimensions of this subsystem have not been determined. Further study to determine whether this subsystem is adequately served by NBS is under consideration.

E. Metric conversion will lead to problems that range from confusion over what measurement unit will be adopted for the revised customary usage to how to overcome the problem of the high current investment in very durable, long-lived non-metric measurement and testing equipment. Testing machines and rolling mills 30 years or more old are common.

\subsubsection{Fluid Flow [13]}

A. New flow standards, recommended practices, and instrumentation are needed for the measurment of low velocities of air and water. Occupational safety and health needs for coal mine safety, industrial ventilation, and indoor circulation require precise measurements at air velocities as low as $0.4 \mathrm{~m} / \mathrm{s}$. which in turn requires a $1 \%$ calibration at $0.05 \mathrm{~m} / \mathrm{s}$ at NBS. Measurements of low velocity circulatory water motions are critical 
in environmental studies; for example, those required for environmental impact statements required for power plant siting.

Improvements in unsteady air flow measurement capability, and development of calibration capability for the dynamic response of wind speed measuring instruments are urgently needed. Wind gusts can be very destructive to buildings, bridges, signs, automobiles, and aircraft.

Universally used standards for fluid flow metering that would constitute a national reference system do not exist. For example, some $85 \%$ of all natural gas in the U.S. today is metered with orifice meters, amounting to current annual transactions of about $\$ 18$ billion. These meters have uncertainties in published values of their discharge coefficients ranging up to approximately $3 \%$, and large economic inequities can result. $A$ responsive program is underway at NBS. New flow standards, recommended practices, and instrumentation are needed for water resource and waste water measurements. For instance, restriction of municipal growth by a few percent due to inaccuracies in establishing sewage plant throughput can be very costly.

NBS has established responsive programs in all the above areas. Other areas of potential activity include:

Multi-phase or multi-component flow technology is finding increasing application in hydraulic and pneumatic transport of materials such as coal, and in pipelining of solid wastes and sewage sludge, and is important in industrial processes, for example, in the paper/pulp industry and dredging.

Another type of flow being encountered with increasing frequency is that in which minute amounts of long-chain polymers are added as a drag reducing agent in water.

Important technological problems have arisen from the use of electrically conducting fluids, and especially liquid metals, as the cooling medium, heat transfer agent or the working fluid in proposed thermo-nuclear power and magnetohydrodynamic (MHD) devices.

Measurement of fluid flows under hostile environmental conditions poses a wide range of new technological problems. Today's velocity measuring instruments are not reliable enough for long-term use in place. Trouble can be associated with fouling, wind, waves, ice, or debris. There is no adequate means of measuring flow in high-velocity flood channels carrying heavy debris. The national need for energy conservation places emphasis on evaluation of fuel metering equipment under the varying conditions of fuel temperature and engine vibration found in motor vehicles.

New measurement capability is needed in both very small and very large rates of flow. For example, the automotive industry is targeting for fuel flow calibrations at approximately $0.4 \mathrm{~g} / \mathrm{s}$. with $\pm 0.2 \%$ uncertainty. The nuclear power industry requires measurement of cooling water flows on the order of 105 $1 / \mathrm{s}$.

Several accomplishments in fluid flow studies at NBS can be directly related to the National Fluid Flow Measurement System study. These include:

(1) Preparation in July 1973 of an internal report entitled "A Survey of Flow Measurements in Water Pollution Control". The survey provides a direct means to establish and improve communications with instrument users in the field.

(2) NBS (Mechanics Division) sponsored a conference on "Flow Measurements as Related to National Needs" in February 1974. Speakers and attendees of over 170 represented views from industry and trade associations, governments, regulatory agencies, instrument manufacturers, standards laboratories and users of instruments.

(3) "Wastewater Flow Measurement [Federal] Interagency Group Discussion of Standards and Methods of Measurement" was hosted by the Mechanics Division in June 1974.

(4) A meeting was held in September 1974 with the "Fluid Meters Standards" committee of the Scientific Apparatus Manufacturers Association, to discuss potential establishment of a national reference system for flow measurement.

(5) A guidebook to standards and methods for the measurement of water flow was published in fiscal year 1975.

(6) New technical programs and facilities have been initiated as mentioned above, in many of the areas of need identified during the study.

\subsubsection{Pressure [14]}

A. No major improvements in existing NBS primary standards for static pressure measurement are expected to be needed for the fore- 
seeable future. A slow extension of NBS capability at the high pressure end of the range is expected to be needed and to occur, in support of new technologies in powder metallurgy, metal forming, coal gasification, and synthesis of materials; unmet needs will exist in such fields as geophysics, equation of state studies, and explosives development.

B. The primary deficiencies in the pressure measurement system lie in its performance at the end-use level and under nonideal conditions. Dynamic pressure measurements are wi thout central calibration support, as are measurements under extreme conditions of vibration, temperature, radiation, or corrosion. The automobile tire pressure measurement system is out of control; there is no practical way today for the motoring public to assure itself of the proper inflation of automobile tires. A measurement assurance program is needed in support of the aircraft altimeter portion of the system-= the present uncertainties may not be compatible with the 1000 foot elevation separations between planes that are standard; calibration liaison with the airlines has been improved by NBS and such a program is being developed. Pressure measurements associated with nuclear reactors are inadequate. Many new pressure transducers are coming into widespread use whose performance and calibration behavior are not reliably known.

C. Improved error analyses and personnel capabilities in the lower echelons of the calibration chains can improve the performance of the existing pressure measurement system far more than anything done at the primary standards level. Both NBS and other agencies are at work on this approach.

Training courses for U.S. Navy technical personnel have been created and are given by NBS to aiz comers. Improved texts and other courses are being developed. A new pressure measurement data evaluation service allows all who wish it to use NBS computational capabilities at very modest cost. A similar transducer evaluation service also exists. A Measurement Assurance Program in pressure is under development. A laboratory evaluation service is being considered.

D. Vacuum measurements for the medium and high vacuum ranges have been wi thout central support in the national measurement system for at least the past twenty years. The large industry dependent upon vacuum measurements has been getting along without any driving force to provide uniformity in the vacuum measurement system. Expert opinions exist which state that this situa- tion represents a severe and unnecessary handicap to American industry. A Delphi study to date has established the need for vacuum transfer standards, primarily for low and medium vacuum and to a much less extent for high and ultrahigh vacuum, thus enabling NBS to respond to real needs and avoid a marginally valuable effort.

\subsubsection{Temperature [15]}

A. Use of electronic thermometers and thermistors has created a whole new domain of problems in medical thermometry, to which NBS is responding by creating a comprehensive program to measure the relatively unknown characteristics of thermistors and small resistance thermometers, and to provide technical leadership for medical standardization.

Regulatory agencies find themselves with many temperature measurement problems. Reducing automobile pollution and increasing mileage requires precision themometry. Nuclear power has been handicapped by inadequate in-reactor thermometry. Commodity manufacturing has its themometry-related problems, but these are not often exposed to outside view.

Major changes are occurring in the worldwide production and use of energy. Most studies indicate that new extensions of existing themometry capabilities will be necessary if the U.S. is to develop appreciable new sources of energy. Relevant areas include superconductive power transmission, geothermal sources, enhancing the efficiency of present power production facilities, effective safety and control of fast breeder reactor plants, thermocline oceanographic heat pump power generation, controlled thermonuclear reactors, and solar power plants.

Work on the temperature scale should be continued. The gas thermometer investigation of the scale integrity should be pressed to an ultimate overlap with radiation thermometry. The extension of the scale through the cryogenic range should be brought to fruition--if necessary, through NBS initiation of an international discussion to this end. Another area of temperature scale research involves the convenient, accurate measurement of temper atures in the $600-2000^{\circ} \mathrm{C}$ range; at present, neither thermocouple nor resistance thermometry is completely satisfactory.

B. In the area of industrial standards, NBS is undertaking basically a liaison role which has two tasks. First, to catalog the standardization activities of the various 
groups, and second, to communicate directly with the individual industries and with the "standards industry" so that they can cooperate in writing standards if they wish.

We found that many commodity manufacturers are interested in thermometry primarily as it relates to the efficiency of manufacture; they show little interest in thermometry applied to the ability of the product to perform its function or to its durability. Tools which can be used to change this situation include a reference service for thermometry expressly intended and publicized to offer technical information on sensors and measurement techniques and locator information on geographic availability of calibration and engineering laboratories, and a wel1-planned Measurement Assurance or Measurement System Calibration program to sample thermometry competence in "willing", selected facilities.

The major new NBS program in medical thermometry has been mentioned above.

NBS has initiated a fieasurement Assurance Program in thermistors, encompassing users, manufacturers, and instrument makers.

Renewed emphasis has been placed on the NBS Precision Thermometry Seminar, with the result that attendance has tripled over the previous average.

\subsubsection{Humidity and Moisture [16]}

A. The measurement of very low water vapor content is, at best, crude. Such measurements are needed in both the earth's upper atmosphere and in other planetary atmospheres, and in the petrochemical, nuclear reactor, and compressed gas industries. Humidity measurement technology is inadequate also for very high water vapor contents and for measurements at both very high and very low pressures, with corrosive gases, or under dynamic, rapidly fluctuating conditions. Calibration procedures are needed for the long path-length spectroscopic techniques.

B. Improved methods are needed for measurement of product moisture content, especially for agricultural crops. NBS has initiated a substantial program in support of measurements of moisture in grain.

C. The rise of consumer information and protection requirements suggests that in the future some consumer products may be required to be labelled to specify moisture content. Such a development would bring state and lo- cal weights and measures agencies into this field and would demand rapid methods of test and inspection. Products of specific current interest include peat moss and firewood (if sold by weight).

\subsubsection{Thermodynamic Properties of Fluids [17]}

Systems of technological interest are almost invariably mixtures, often multiphase. Experimental determination of all of the needed data is precluded by the large number of systems of possible interest and of the rmodynamic states needed to characterize each. Predictive methods based on theoretical models are essential. Especially useful are those models which result in equations of sufficient simplicity to be used in engineering calculations.

A good theory of pure liquids is needed, upon which to build mixture theories. Theoretical expansions are needed of mixture properties around those of pure species, including development of understanding of the limitations of usual "mixing effect" approaches.

Growing demands exist for data for systems under conditions which are hard to obtain and to control in the laboratory, for instance, of reacting heterogeneous sys tems at elevated temperatures. Needs are clear in such areas as fire research, chemical process plant design, coal gasification, military weaponry, and nuclear reactor safety. Since many applications in this area require calculations which are of only an interim nature, a range of theoretical models providing varying degrees of accuracy is an ultimate goa 1 .

Development and validation of predictive theories requires a solid data base regarding the properties of specific real substances, pure and mixed, which substances can be chosen to be also of prime technological importance. Mixing effect data are extremely important and may represent a very small difference between two large numbers, so that high precision in measurement is essential. NBS expertise in and dedication to precision measurement make it an especially appropriate source for this data. Lack of an adequate data base has resulted in very slow progress in the development of predictive methods.

Even with the reduction in data-taking demands made possible by predictive methods, the volume of data that must be generated by actual measurement is still extremely large. Automation is essential. Particular emphasis is required for pressures, 
compositions and high temperatures. NBS activity in this field is essential and underway, but needs considerable expansion.

Data are of particular importance concerning immiscibility diagrams, in the vicinity of critical lines and critical points of various orders. Further, work is needed on the development of a single unified description of the entire PVTX surface, eliminating the separate nature of the descriptions around critical points. Data are needed to allow testing of present indications that relatively simple methods can be developed for the prediction of thermodynamic properties of fluids at temperatures above approximately twice the critical temperature. NBS has contributed both broadly and deeply in the development of methods for the description of thermodynamic properties in the critical regions of material systems.

In recent years, optical methods have been developed for measurement of thermodynamic and transport properties of fluids. These methods have considerable potential in situations where equilibrium states are hard to obtain and to maintain. The future will see the development and use of many such methods, and they will become a major part of the NBS program.

Many industrial applications are for data to be used under conditions of (at best) transient themodynamic equilibrium. Further, transient equilibrium experiments are of considerable use in obtaining data at very high temperatures. The development of an extensive set of transient equilibrium measurement techniques would be of considerable utility.

This program area works in close cooperation with the National Standard Reference Data System activity of NBS.

\subsubsection{Cryogenics [18]}

A. A complete and comprehensive measurement system for the liquefied natural gas industry needs to be developed, with special emphasis on quantity gaging in storage and ship tanks, flowmetering for determination of both mass and heating value, and basic measurements of thermal and mechanical properties of structural materials.

Superconductivity connects cryogenics measurements and data to the electrical power industry, for power transmission, generation, and storage. Knowledge needed includes heat transfer rates, behavior of helium refrigerant flow systems (including the response to instabilities), and the degradation of the superconductors with time and stress.

Some parts of the cryogenic measurement system seem to be characterized by adequate quality assurance, but it appears one should have less confidence in other parts of the system. Pressure measurements, which are probably the measurements most widely made in all of cryogenics, specifically need attention. Especially glaring at this time is the need for a new kind of measurement, namely one that describes the "quality" or "availability" of the commodity; specifically, we refer not to the flow measurement of liquefied natural gas, for example, but to the need to measure its potential heating value.

B. The cryogenics case study of the National Measurement System (the history of liquid nitrogen flowmetering program) documented the complete process that must be undertaken to provide a complete measurement service. As a result, all new work proposals are now deliberately constructed to include all three necessary elements: Measurement Science, Data Base, and Technology Transfer (including safety, interstate and international cooperation, effective use of the NBS Office of Weights and Measures, and training).

This program area has become more sensitive to the measurement sys tem concept in all its activities. For instance, an inventory of our measurement services is the first step in a deliberate process which will either revalidate existing programs or stimulate changes in our measurement services.

Market impact and issue studies have long been a way of life for this program area. However, the National Measurement System study differs markedly from previous efforts. First, it included a backward look--our first--to document a completed program. Second, we approached it not only as a study of the System, but also as a study of how to study the System (research on research). Thirdly, we emphasized the measurement system and measurement science, rather than technological impact. Without the impetus of the study, we would most likely have lost the understanding we now have of a "complete" program, and our role in the infrastructure of the measurement sys tem. 


\subsubsection{Electricity $[19,152]$}

A. The field of precision static electrical measurements is substantially under control through NBS continued efforts. The major need is for the publication of tutorial material by the current senior generation to pass its expertise along to the younger generation. The system is presently ill equipped to face the future of dynamic measurements.

Automatic test and control systems require the introduction of time as a measurement parameter. Specifically critical areas include pulsed component characteristics, dynamic performance characterization for modern signal conditioning and data conversion devices, and methodology for characterizing precision $A C$ and $D C$ sources and measurement devices with respect to settling time.

The emergence of electrical measurements into the "real world" of the production line via the automatic system has introduced a host of new parameters. Areas requiring significant effort include the investigation of transportable standards for validation of static and dynamic system performance, techniques for characterizing sources and measurement devices with respect to switched or dynamic loading, prediction of long-term performance reliability and lifetime from short-term evaluations, noise standards and methodologies, improved transportable $D C$ standards and dissemination at higher voltage levels, characterization of the AC line voltage (waveforms, transients, etc.), inclusion of a capability for environmental control and variation in calibration systems, and extension of Measurement Assurance Programs in these fields.

Recent work at the leading edge of measurement technology for electronics has resulted in the need for new or higher-accuracy measurements in such areas as dielectric hysteresis, phase differences, power, non-sinusoidal high-crest-factor signais, and reduction of $A C$ calibration uncertainties to $10 \mathrm{ppm}$, at least over the audio range.

Longer term, "frontier" areas include measurement problems at the systems level; evaluation and standardization of system software; calibration of medical equipment; replacement of standard cells; measurements of impulse noise and other parameters; basic work on the physics of dielectric absorption, component drift, device noise, failure mechanisms, switches, and relays, and provision of improved accuracy for virtually all dynamic measurements for in-process probing of integrated circuitry during manufacture.
In general, NBS needs to provide the same measurement leadership in these newer areas of dynamic electrical measurements as it has in the older ones of static measurements. The electronics community needs to be kept informed about NBS work-in-progress.

B. The microstudy has led to the initiation of an effort within this program area through reprogramming to address the metrology problems associated with high speed measurement of electrical parameters. In September 1974 a workshop involving the manufacturers and users of electronic measurement components, modules and instruments was sponsored by the Electricity Division to identify the scope of the problem and areas of opportunity for investigation. The workshop revealed (1) traditional metrology services are still needed (some areas can stand improvement), (2) standardized and valid test procedures for determining the temporal characteristics as well as the accuracy of devices under dynamic conditions are sorely needed, and (3) methods for determining pulse conditions must be developed [152].

Investigations are proceeding to establish standards and instrumentation to investigate high-speed and analog-to-digital and digital-to-analog conversion modules; to establish methodology for the proper support and implementation of electronic test equipment of high accuracy; and to provide an accurate measurement base for the semiconductor industry at the 10-volt level.

A program has been started to generate a series of tutorial publications covering various aspects of electrical metrology useful to personnel of a typical standards or calibration laboratory. An effort is being made to establish an Electricity Division newsletter and to publish overview articles in other periodicals.

A strong program in dielectric loss tangent measurements for superconducting transmission cables is being undertaken with the support of the Energy Research and Development Administration.

The study led to work in new areas of Measurement Assurance Program activities, among them inductance, dc voltage at 10 volts, and energy.

There is an increased awareness by the division staff members of market analysis techniques and tools, and the collection of economic data. 


\subsubsection{Electromagnetics $[20,21]$}

In the past, the National Electromagnetic Measurement System made an essential contribution to the development and maintenance of the military systems for early warning radar, side-looking radar, the guidance of terrainfollowing airplanes, the guidance of weapons, navigation, and telecommunication on which our defensive posture relies very heavily. As usual, commercial technology has followed the military lead, so that today six trends can be seen that will determine the development of electromagnetic measurements and standards in the next few years:

1. the rapid expansion of satellite communications into a world-wide system;

2. the rapid expansion of electro-optic technology, particularly fiber-optic communication systems;

3. the full exploitation of electromagnetic remote sensing, particularly in agriculture;

4. increasing reliance on electronic servo control of industrial processes and vehicles;

5. worsening of the problem of electromagnetic interference, leading to stricter regulation of both sources and victims;

6. increasing public awareness of non-ionizing radiation hazards.

In response to these trends, the NBS Electromagnetics Division is being reorganized into five programs:

1. Guided Wave Metrology, which provides the basic rf and microwave measurement and calibration services, and develops standards and measurement technique for millimeter wave systems and fiber optics;

2. Electromagnetic Sensing Metrology, which performs the research and development necessary to enable electromagnetic waves to be used for remote sensing and characterization of inaccessible dielectric anomalies;

3. Electromagnetic Interference/Radiation Hazards, which develops standards and measurement techniques to determine the emission and susceptibility of devices of and to interfering fields, and the strength of fields to which people and equipment are exposed;

4. Signal Wave form Metrology, which develops standards and measurement techniques to characterize transient and modulated waveforms, and systems designed to transmit them in the time domain;
5. Antenna Systems Metrology, which develops measurement techniques and provides measurement services to characterize complex antennas and associated systems used for satellite communications.

This reorganization is a direct response to information collected for this study of the National Electromagnetic Measurement System.

\subsubsection{Medical U1trasonics [22]}

A. The national measurement system for medical ultrasonics is presently fragmented, uncoordinated, and inadequate. Commercial instruments to measure ultrasonic power are not yet on the market. The accuracy of the commercial scanning systems for the measurement of ultrasonic beam profile and field pattern is not yet known. NBS initiated a program in this field several years ago, and has begun to supply the central measurements and standards capability that will allow this system to take an adequate shape.

B. Within a year, NBS will have developed a new calorimetric power standard to supplement our present technique and a scanning system which will provide the information on transducer field pattern, intensity, distribution over the beam area and other quantities of interest. There needs to be developed simpler systems for use in the field. A very high priority item is a reliable, rugged, low-cost transfer standard for ultrasonic power so that NBS accuracy can be disseminated to users on the broadest possible basis. This transfer standard should be developed at NBS and subsequently manufactured by private industry.

C. Ultimately, NBS should provide a measurement assurance program in ultrasonics with manufacturers, Bureau of Radiological Health, and other principle laboratories such as universities and major medical centers. These latter laboratories could then provide measurement support to hospitals and other users.

\subsubsection{Acoustics [23]}

A. The current NBS program in acoustics and noise is a direct result of studies similar in intent to, but preceding, the National Measurement System Study. These studies indicate the significant increase in the number and scope of legislative actions directed toward noise control which have recently taken place. It is likely that this increase will continue. In order to ensure the promulgation and enforcement of equitable noise 
emission and workplace noise regulations, technically well-based noise measurement procedures are required. Continued attention on the accurate and objective collection of noise emission data bases and the evolution of improved acoustical measurement methodologies is needed.

There are numerous identifiable deficiencies in the structure and interconsistency of acoustical measurement procedures and documentary standards; simplification and consistency are badly needed.

Neglect of technical and economic impacts and large magnitudes of inaccuracy and imprecision have long characterized the field of acoustical measurements; attention to these matters is essential. The imprecisions inherent in existing measurements may introduce inequities in trade. The promulgation of Federal noise control legislation has forced the relevant Federal agencies and affected private sector groups to consider the impacts of noise emission and workplace noise levels.

Similarly, lack of understanding of the performance limitations of measurement and analysis instrumentation has led to incorrect usage and technically unreliable data. There is a continuing demand for improved accuracy and precision in both the development and calibration of acoustical measurement instrumentation and in the evolution of improved measurement methodologies. In particular, procedures for the verification of proper performance of commonly used instrumentation, such as sound level meters, integrating noise exposure monitors, and audiometers, are urgently needed.

Proposed changes in occupational safety and health regulations would require a major increase in the number of audiometers, and trained audiologists and otologists.

Damping materials to control noise are not well characterized largely due to inadequate measuring technology. Complete and adequate specifications and general knowledge regarding vibration isolators is lacking.

Ultrasonic flaw detection is badly in need of more reliable and more precise means of system calibration. The compatibility in results of ultrasonic non-destructive testing between plants and between companies range from good (at best) to entirely unacceptable. Needed are the development and dissemination of evaluated measurement methodologies, well-characterized physical standards, and reliable technical data.
B. A number of elements are suggested for incorporation in the existing NBS program in order to adapt to the changing needs of the technology. These elements include:

(1) Thorough study of the effects of environmental factors such as temperature and humidity upon the properties of acoustical measurement systems and system elements. These factors become increasingly important as interest is extended to include acoustical measurements conducted over long time periods.

(2) Provision of performance testing services for acoustical measurement systems such as sound level meters.

(3) Strengthening of the NBS program of research in the relevant basic physical phenomena, and the provision of important measurement facilities for this research. The absence at the NBS Gaithersburg site of semi-anechoic, airborne sound transmission loss, and structure-borne sound test facilities has proven to be a severe handicap, not only to NBS involvement in the infrastructure, but also to continued professional growth of the staff.

The National Measuremerit System study has helped to stimulate the acoustical cal ibration program for audiometers, and plans are underway to develop a measurement assurance program for audiometer manufacturers. If this is successful, it will be extended to include the large number of laboratories calibrating audiometers for industrial use. The need for a detailed manual on audiometer care and calibration is to be studied. The proper calibration, maintenance and operation of this type of acoustical measurement instrumentation will become increasingly important to our society as hearing conservation programs become mandatory and more widespread. Audiometry standards are needed to measure what really is a measure of loss of hearing.

Continued interaction with the national and international acoustical measurment standards community provides an important means to reduce system deficiencies by the dissemination of NBS acoustical measurement expertise, and contributes tnward expansion of the technology and promulgation of equitable noise regulaticris.

\subsubsection{Radiometry and Photometry}

A. Radiometric and photometric measurements are difficult to make, expensive, and generally have very poor accuracy. This is due in part to the nature of the measurements, 
but the situation is much worse than necessary due to the lack of inexpensive standards and of adequately trained people to make the measurements. NBS is responding in both areas.

B. The major result of the Study was creation of the Council for Optical Radiation Measurements (CORM). CORM is an organization of several hundred members which has served to focus attention on the needs for measurements in the field of optical radiation and to provide programatic guidance to NBS.

A specific result was stimulation of the CORM report "Pressing Problems and Projected National Needs in Optical Radiation Measurements--A Consensus of Services Desired of NBS".

A new NBS program in the field of optical radiation measurements has evolved, by reorganization and reprogramming. It includes a five-year program plan, intentions of further internal division and Institute shifting of funds, and attraction of visiting scientists. This new NBS program emphasizes the creation of new spectral and detector standards, the development of a new photometric SI unit based on radiometry, and the establishment of well-documented, efficient calibration service and Measurement Assurance Program (MAP). Finally, and possibly of greatest importance, plans are now being carried out to produce a Self-Study Manual to provide the training in basic concepts and laboratory techniques required in the national measurement sys tem.

NBS arranged two Optical Society of America technical group discussion sessions. It conducted an international meeting focused on upgrading the U.S. meteorological radiometric network. Further, NBS organized a radiometry workshop at Electro-Optics Conference and Exhibit in New York, two symposia for fall 1974 meeting of the Optical Society of America, and workshops on radiometry and photometry for the November 1974 ElectroDesign Conference.

By 1980, NBS will have made significant progress in its program of "making 1\% accuracy in radiometry commonplace". Commercial instruments will have reached a new level of sophistication and efficiency. A wide variety of solid state sources and detectors and electrically calibrated pyroelectric radiometers will be packaged with appropriate mini-electronics and computers for "shirt pocket portability". Quantitative applications of optical radiation will begin to increase substantially. Remote sensing, solar energy applications, medical therapy, and industrial processing will begin to use routinely what is now considered state-of-theart radiometry and photometry. Day-to-day demands made on NBS relative to radiometry and photometry will increase significantly. Further, as the NBS Measurement Assurance Program verifies that $1 \%$ measurements are being made, applications and demands requiring $0.1 \%$ will begin to emerge.

\subsubsection{Spectrophotometry [25]}

A. The more complex measurements and those in which high accuracy is required are generaliy not too successful. Promotion of these measurements to their fullest potential requires careful study by workers with sufficient radiometric training to be able to recognize the significance of the fine points of the measurements. Such workers can determine the appropriate techniques and equipment for the measurement and translate them into equipment which can be used under ordinary laboratory conditions by the present laboratory personnel. They can provide clear instructions and appropriate standards to back these personnel in their work.

A major driving force in this field stems from performance and economic benefits to be gained by replacement of human observers by machines, in the repetitive inspections required in such areas as quality control.

B. The microstudy defined the fact that inadequacies in NBS efforts in this field during the later 1960's had led to a situation where a major segment of the measurement system was substantially out of control, with NBS doing virtualły nothing about it.

In 1971 NBS initiated by reprogramming a response to the needs defined above:

a. A Measurement Assurance Program

b. Thorough evaluation of procedures specified in existing documentary standards, to separate sense from nonsense.

c. Provision of key material standards, either directly or through non-NBS suppliers.

d. Various lines of communication have been set up with the spectrophotometric community, including working relationships with instrument manufacturers through the Council on Color and Appearance (MCCA), a trade organization of manufacturers of instruments, and participation in CORM and the self-study manual program of the Optical Radiation Section.

e. Resolution of discrepancies in the scales of absolute reflectance among NBS, NRC (Canada), and PTB (Germany), of particular importance for support of the paper industry. 
The National Measurement System in Spectrophotometry is currently far from living up to its potential value. A relatively modest program in NBS, multiplied by active cooperation with instrument manufacturers and commercial laboratories, can provide the support which is required for full realization of this potential.

\subsubsection{Far U1traviolet Radiometry [26]}

A. Primary radiometric standards, both sources and detectors, exist throughout the far ultraviolet spectrum (wavelengths less than $300 \mathrm{~nm}$ ) and are fairly well developed. However, they are usually too complicated or specialized to be applied in practical situations. Transfer or secondary standards are absolutely necessary. Transfer sources are not very well developed in this region; no reliable sources exist below $115 \mathrm{~nm}$, and there are currently no. known plans to develop them. Uncertainties in the standards for the wavelength region between 115 and $250 \mathrm{~nm}$ are typically no better than 5\%. Transfer detectors are fairly well developed and are currently available from 19 to $320 \mathrm{~nm}$ with uncertainties in the $5-10 \%$ range.

The primary significant deficiency in the field is the lack of suitable interactions among almost all of the areas identified as having a measurement need or responsibility and organizations possessing the available primary and secondary transfer standards. In particular, very little use has been made of the resources and leverage that could be obtained by working closely with the secondary standards laboratories and the instrumentation industry. One possible explanation for this situation is that the basic standards are still largely in the research stage, and those that do exist have not been sufficiently publicized. That is to say that, in essence, the measurement network is still in the development stage.

If NBS is to meet its responsibility as a key component of the ultraviolet radiometry national measurement system as it is now evolving, it must maintain its present expertise and consider the following immediate programs where it is deficient.

(1) Develop reliable transfer source standards (a) in the region 110-165 nm, with uncertainties of $1 \%$, and (b) below $110 \mathrm{~nm}$, with certainties of $10 \%$.

(2) Develop a special irradiance source standards for the region 110-250 nm, with uncertainties of $1 \%$.
(3) Develop both the hydrogen arc source and the NBS synchroton (storage ring) as complimentary primary sources of absolute spectral radiance.

(4) Extend the calibration range of detectors to fully cover the range $5-400 \mathrm{~nm}$, with uncertainties of $1 \%$ above $115 \mathrm{~nm}$ and $10 \%$ below $115 \mathrm{~nm}$.

(5) Support a program where standards from the different sections within NBS can be cross-calibrated and intercompared.

(6) Initiate more workshops with various interest groups similar to successful meetings which involved the health and safety regulatory agencies, NASA, and fusion scientists. Photochemistry and biomedical application should be the first fields where NBS should generate a new initiative.

(7) Initiate a formal measurement assurance program (MAP) for all ultraviolet radiation services.

B. We have identified a wide variety of users of ultraviolet radiation with whom we had little, if any, contact before this study. Upon close examination of the radiometric requirements of this rather large group we have decided: (1) to reprogram our standard source effort in order to emphasize the development of transfer standards of spectral irradiance; (2) to reprogram our standard detector effort to include wavelengths up to $400 \mathrm{~nm}$; (3) to push for uncertainty levels approaching 1\%; (4) to coordinate more close$7 y$ the independent efforts of the various sections within NBS working on uv standards. Previous to this study, most of our work was directed toward extending the wavelength region of our primary standards to as short a wavelength as possible; we concentrated mostly in standards of spectral radiance; we assumed that 5-10\% uncertainties would satisfy just about any conceivable user.

\subsubsection{Optics [27]}

A. The field of photography has problems with measurement of low photographic densities which stem from the use of opal glass in light collection systems instead of integrating spheres. New primary calibrated standards are required. Extension of the range at the high density end is also needed.

The graphic arts industry is getting by on the reflection density standards that are available, albeit not too happily. Microfilm industry people are happy with the 
microscopy resolution chart, but not about its price. High resolution lens testing and standardization has room for improvement. It is recommended that NBS:

a. Continue the development of a primary calibration facility with its intended purpose of satisfying users' needs in transmission density measurements .

b. Acquire a new reflection densitometer, develop suitable primary reference standards and have them calibrated by the appropriate NBS group.

c. Maintain the present lens test measurement service without further direct investment in it.

d. Continue the program of expanding the application of microdensitometry into allied fields, such as the general evaluation of photographic images and interferograms.

e. Continue efforts to develop a physical standard applicable to optical and electron microscope dimensional measurements.

Recommendations for actions when time and resources become available are:

a. Determine the appropriateness of and industry interest in an active users' group in the optical industry.

b. Investigate the feasibility and desireability of NBS standard reference materials for reflection density applicable to graphic arts and related fields.

B. The results of this present study have been:

a. The definition of the relationship of NBS to the users of its measurement services. Little had been known by NBS of the composition, nature, and dependency on NBS of $i$ ts customers.

b. The discovery by NBS, in the graphic arts industry, of a group of potential users of NBS services in reflection densitometry. Since there is no mandatory dependency on this group at NBS, its use of density standards was unknown.

c. The knowledge of its users which allows NBS to place in context the services asked of it by the Council on Radiation Measurement.

d. The redirection of NBS programs toward measurement applications of optics, such as the use of optical microscopes for measuring line widths on integrated circuit masks, rather than optical testing per se.

\subsubsection{Lasers $[21,28]$}

A. Measurement technology will expand from measurements on lasers to measurements on laser systems. The short term need in power and energy is for an inexpensive service to assure standards maintenance at the user's site; the long term need is for the development of self-calibrating systems with an automatic or remote check against SI standards. High power measurements, in-beam profile measurement technology, and picosecond pulse metrology all need to be established or substantially improved.

In the longer term, integrated optics will become a reality and measurements of the lasers in such devices will be necessary; new instrumentation will come into existence: optical ammeters, ohmeters, phase meters, and network analyzers.

International competition will require increased U.S. participation in international laser standards groups.

B. The measurement of laser frequencies is almost a sole source effort of NBS because of the direct traceability of these measurements to SI standards. The NBS-developed technology leads the field, and at present is far ahead of its time.

An NBS role in measurements for lasers for use in power generation systems has been developed as part of NBS $^{\circ}$ response to the energy crisis.

Needs for NBS development of critical data and measurement technology required for the development of high power lasers, for laser isotope separation in the near term and for laser fusion in the far term, have been documented, and additional marketplace needs for these types of laser have been identified and quantified.

Laser parameter measurements other than frequency, power, and energy are not based on SI units, and measurement responsibilities have passed to the private sector. It is not expected that NBS will become heavily involved in the other parameters unless a severe measurement conflict is encountered in the private sector involving a federal agency. At the present time, none has been identified, and none can be projected.

It is estimated that the laser parameter measurements requirements for NBS will remain significant for three to five years, and begin to reduce to a caretaker role and eventually to a self-calibrating service through the direct dissemination of an SI standard. The next major measurement and standards activity involving lasers should be the measurements and standards on laser systems. At this time, the informationprocessing and communication applications of integrated optics is the number one choice for future NBS measurements and standards efforts. 
3.5.22 Physical Properties of Atoms and Molecules [29]

A. Surveys of the data wanted by potential users indicate that some scientific areas very important to current technology, e.g., electron transport coefficients, are being ignored by the U.S. research community. Without improved data sets as the basis for more effective modelling and for more effective analytical and diagnostic measurements, development of such technologies as controlled thermonuclear power and high power lasers for isotope separation will be handicapped.

Basically, the service to be provided by the NBS atomic and molecular portion of the measurements system is to focus the output of the atomic and molecular physics community into the generation of an adequate and reliable data base for mathematical representation of the principal properties of plasma devices and to permit mathematical analysis of factors that determine efficiency. Corresponding application of the data base will occur in the sciences, notably plasma physics, aeronomy, astrophysics, and aerodynamics.

This will involve the invention of new measurements to obtain properties of various species of atoms and molecules not measurable by traditional methods, and will be concentrated on the data needs of the following a reas :

(1) Controlled Thermonuclear Research. Current research efforts in this field have a need for new data, particularly properties of multiply-ionized atoms.

(2) Laser development and applications. Atomic and molecular data, particularly on molecular and atomic excitation cross sections by electron impact for various species, are currently needed.

(3) Industrial processes requiring atomic data. This is an areas in which NBS has not been substantially involved in the past but to which it is currently making contributions (e.g., work on MHD coal-fired generators and commercial lighting). Applications of this type require close personal contact with industrial research and development efforts and NBS staff specializing in this type of problem.

(4) Commercial measuring devices which require atomic data for their design or interpretation. While there appear to be a number of such devices currently in use (electron spectrometers for chemical analys is [ESCA], mi croprobes, comnercial spectrometers of all types, etc.) very little has been said of their need for atomic and molecular data generation services simply because these needs have not been assessed, and users or developers of these devices are not closely coupled to atomic and molecular data generation activities either at NBS or elsewhere.

(5) Aeronomy and atmospheric science. NBS activity directed to these areas will probably decrease as a result of high prior$i$ ty of other areas.

\section{B. Specifically recommended are:}

(1) Improvement of the NBS coordination with gruops developing and testing methods of using atomic and molecular data for industrial design of new plasma devices and for introducing improved efficiency factors in existing devices.

(2) Re-examination and expansion of its atomic and molecular data compilation, evaluation and dissemination activities to ensure that maximum effective utilization is made of the data output potential of the entire atomic and molecular community, the needs of the most urgent development projects are met by development and issuance of specialized data sets, and that the goal of realizing a generally accessible, generally useful and thoroughly reliable base of data and methodology directed to the needs of the industrial and scientific communities be kept in view.

(3) Continuation of NBS support of measurement activities of the entire atomic and molecular physics community through development and testing of measurement techniques for properties needed by and not available to the user communities; execution of selected benchmark measurement programs; re-examination of transfer standards for measurement of gas density and radiant flux; and continuation and strengthening of NBS sponsorship of critical reviews and evaluated compilations.

\subsubsection{Surface Properties [30]}

A. Most of the measurement methods now in use for surface characterization have become commerically available within the past ten years. At this time, there is a total lack of standards, standard procedures, and standard materials to support surface characterization measurements. In short, there is no established measurement system for the measurement of surface properties. The major range of applications of this measurement 
technology--energy, defense, advanced materials development, environment, health and safety, productivity, and transportation-clearly indicate that a functioning system is needed.

B. Many surface properties and processes (e.g., electrical properties, optical properties, adhesion, bonding, catalytic activity, plating, durability, corrosion, decoration, grain-boundary segregation, lubrication, surface reactions, and biocompatibility) are being related to three types of surface characterization, namely surface composition, surface atomic structure, and surface electronic structure. Conversely, improved surface properties and processes result from the control, design, and measurement of surface composition, surface atomic structure, and surface electronic structure. It is recommended that NBS stimulate the growith of surface science and technology by showing and exploiting the relationships between surface characteristics and surface properties or processes.

\section{c. Other forms of surface character} ization (e.g., nature and distribution of defects on a surface, the surface topography, and the nature and area of exposed facets) are expected to be required in the future for particular scientific and technical applications. It is recomended that NBS maintain an awareness of such needs and be responsive to them.

D. No standards or standard procedures now exist for the reliable measurement of surface composition. It is recommended that NBS support the recently extablished ASTM Committee E42 on Surface Analyses in its efforts to develop needed surface standards.

E. Many measurement needs exist for the popular electron-spectroscopic methods for determining surface composition (Augerelectron spectroscopy and $X$-ray photoelectron spectroscopy) before quantitative results are possible. Proposed NBS programs to meet these needs have been endorsed by instrument manufacturers and users. It is recommended that NBS respond to these needs with a vigorouse program.

F. Surface atomic structure is currently being determined by low-energy electron diffraction (LEED) for ordered surfaces; the potential exists for the determination of local atomic structure from the angular distributions of photoemitted electrons or of Auger electrons. It is recommended that NBS not be involved at this time in the development of LEED on account of the cost and of similar work being performed elsewhere. The potential of the other techniques for detemining local atomic structure should be explored on account of their likely suitability for general applications.

\section{G. Many techniques are being used to} determine surface electronic structure but considerable uncertainty remains in the proper interpretation of the measurement data. It is recommended that NBS theoretical and experimental effort be used to resolve these measurement problems.

\section{H. Most methods for the characteriza-} tion of surfaces can be employed only in an ultra-high vacuum environment and some of these methods can only be employed on relatively ideal (i.e., single-crystal) surfaces. It is recommended that NBS develop measurement methods that can be used in less ideal circumstances. Specifically, it is recommended that NBS develop measurement methods for the characterization of highly dispersed catalysts in their working atmosphere.

\section{Many of the present and potential} users of surface-characterization instruments do not have extensive experience in surface science or technology and have difficulty in selecting instruments to meet their needs or in operating these instruments satisfactorily. It is recommended that NBS sponsor short courses or workshops, perhaps in collaboration with educational organizations, to solve this problem.

J. Conflicts might arise in the future between surface standards developed in the United States and those that might be developed in other countries, unless channels of communication are established to avoid this possibility. It is recommended that NBS maintain an awareness of surface standards developed in other countries and act to prevent conflicts.

\subsubsection{Ionizing Radiation [31]}

A. External trends producing new needs to force changes in the measurement system include the expansion of nuclear power; the breeder reactor program; fusion research; concerns for safeguarding nuclear fuel materials; the expanding needs of regulatory agencies, especially at the state level; expanding use of radioactivity in medicine; new radiations being proposed and tried for radiation therapy of cancer; environmental concerns; and concern for the safety of personnel working in this field. 
Many users in the field are not achieving the accuracy of measurements that they need. This has led to an extremely strong trend at NBS: transfer of enhanced calibration accuracy out to the users, through a very vigorous activity in measurement assurance, establishment of secondary standards laboratories, and development of high-quality transfer instruments.

All regulators of radiation need to be on the same measurement scale. The great majority of state health departments with responsibility for radiation control would be benefited by a program of technical assistance in radiation measurement. A highquality measurement assurance laboratory is needed to test personnel radiation monitoring services. Monoenergetic neutron calibration fields are needed to test existing, and for use in developing improved, neutron personnel monitors. The medical radiation community needs wider dissemination of NBS dosimetry calibrations through further development of a regional calibration laboratory system, development of primary absorbed dose standards where they do not now exist (for high energy $X$-rays and for fast neutron radiotherapy), extension of a system of quality control throughout the approximately 10,000 institutions doing nuclear medicine; and straightening out of problems with dose calibrators in collaboration with manufacturers and by provision of appropriate check sources. The measurement system for radionuclides used in medicine is out of control.

A rigorous measurement system to prevent unauthorized diversion of nuclear fuels is essential. In the nuclear fuels measurement system, the dominant needs for highaccuracy measurement are for nuclear safeguards, not for buyer-seller equity, and the nuclear industry's major need is for a comprehensive, nationally-based measurement assurance system for demonstrably viable fuel material measurements.

In the area of reactor design data and operations, needs are for standards for neutron cross-section measurement in support of the liquid metal fast breeder reactor, the high temperature gas-cooled reactor, and thermal neutron power reactor programs; and for measurement standards for in-reactor measurements of neutron flux and spectra and fission rates in fuel elements. For fusion reactors, data will be needed for shielding, heat transfer element design, tritium breeding design, neutron cross sections, integrity of structural materials, and induced radioactivity problems.
Radiation measurement for national defense has needs in the area of high-intensity pulse $X$ - and gamma-radiation measurement, and high flux d.c. electron measurements. Needs exist for environmental radioactivity standards and measurement assurance testing. For science, a data compilation effort on charged-particle stopping powers, ranges, straggling, and delta-ray production below about $10 \mathrm{MeV}$ is needed. Adequate safety measures in the use of radiation equipment is the chief need in the large variety of mis cellaneous applications of radiation.

In summary, there is often a need for new NBS ionizing standards where they do not exist; existing standards are usually satisfactory. There is a great need for measurement assurance, especially where regulatory requirements exist. A need exists to help the poorly-qualified user--training, convenient laboratory standards, handbooks for guidance. A single measurement system under NBS leadership is needed to help both regulators and users. Needs for NBS to play its traditional "independent third party" role are often found.

\section{B. Although the Ionizing Radiation study} has played a role in the impacts listed below, it must be recognized that none of them originated from the study. The role of the study has been to confirm needs previously recognized; to give quantitative information on needs and the structure of the measurement system; and to give coherence, completeness, and logical structure to the sometimes fragmented efforts on evaluation of needs and preparation of NBS responses to those needs. The study has also identified areas where a response has not yet been fully developed: (1) in the area of Miscellaneous Radiation Applications, how does INBS respond to the need for adequate safety measures in the use of the radiation equipment? (2) extension of $X$-radiation calibration traceable to NBS to all hospitals and clinics (see $4 \mathrm{~b}$ below); (3) a need to extend a system of radioactivity measurement quality control throughout the 10,000 institutions doing nuclear medicine ( 2 and 6 below are partial answers).

Some of the specific impacts are:

\section{Assessment of the Nuclear Fuel}

Materials Measurement System. This specific study was instigated to develop better understanding of the measurement needs related to the nuclear fuel cycle. The program resulting has become the top priority new program in NBS at this time. 
2. Proposal of a National Radiation Measurements Calibration System. In cooperation with the Conference of Radiation Control Program Directors of the States, a program was developed for NBS to help the States in upgrading the radiation measurement capability. The program includes:

(1) detailed assessment of equipment, staff, capabilities, and needs of the various State health departments resulting in a detailed plan for the remainder of the program, (2) development of prototype transfer standard instruments and radiation sources, and (3) provision of specific standards and necessary training to States and regional calibration laboratories.

3. Development of a Calibration Facility for Neutron Personnel Monitoring. With the support of the former AEC, NBS has developed beam-filter sources of neutrons at 2 , 25, and $144 \mathrm{keV}$ using the NBS reactor. Initial calibrations are being made.

4. Identification of "Honest Broker" or "Independent Third Party" Roles for NBS.

a. Quality Assurance program for suppliers of personnel monitoring services. The NBS role here, as worked out with the States, the Bureau of Radiological Health, and the Nuclear Regulatory Commission, will not be to furnish this service to the suppliers, but to supervise and assure the NBStraceability of another laboratory which will actually carry out the service function.

b. Extension of reliable radiation calibrations to hospitals and clinics. Although the radiation measurements for $X$-ray and electron treatment at many of the larger institutions are in satisfactory shape through calibrations by NBS, the two existing regional calibration laboratories or by consulting radiological physicists, there are thousands of smaller hospitals and clinics where the calibrations are non-existent or out of date. The NBS role here appears to be to activate the system through having codes of good medical practice and/or State regulatory requi rements which require calibration of instruments and $X$-ray machines at appropriate intervals (e.g., two years for good quality instruments). This role is being developed in cooperation with chiefly the medical physics community.

c. Environmental radioactivity measurements. The Nuclear Regulatory Commission (NRC), the Environmental Protection Agency (EPA), the States, and the reactor-operating electric companies all have a stake in the environmental radioactivity measurements. At the beginning of this study, the various interested groups were proposing various schemes of duplicating measurements to check up on each other, a highly cost-ineffective procedure, to say nothing of the political squabbles which could result. This has been effectively resolved by choosing NBS to play the role of the "independent third party" and by both NRC and EPA agreeing to establish traceability to NBS, and the States being traceable to one of them. This is now written in NRC agreement-State contracts. In the event of disagreements on measurements, NBS will be called in to resolve the dispute as an "independent third party".

5. Establishment of a Measurement Assurance Program for Traceability to NBS of Radiation Measurements Made for Regulatory Control. In connection with $4 c$ above, a measurement assurance program has been established with the NRC Health Services Laboratory in Idaho, the EPA NERC-LV laboratory in Las Vegas, and some measurement assurance tests have been carried out for nuclear reactor operating power companies (in connection with the standard reference materials program). Under this program the States are made traceable usually to the NRC, rather than directly to NBS.

\section{Establishment of a Standards and} Measurement Assurance Research Associate Program for Radiopharmaceutical Manufacturers. Through the Atomic Industrial Forum and the support of the number of radiopharmaceutical companies, an NBS Research Associate from industry has been acquired who will help the radiopharmaceutical manufacturers to estab1 ish and test their own measurements.

\section{Confirmation of the Need of a} Neutron Standards Program for Nuclear Reactor Design Data and Operations. The NBS Neutron Standards program was started based on an Issue Study done in 1971. The present study confirms needs identified earlier, but with more emphasis on those related to the controlled thermonuclear reaction program for nuclear energy using fusion reactors. The neutron standards program has been funded by both NBS and ERDA, and is now at full strength.

\section{Development of High-Intensity X-Ray} Calibration Sources for Defense Department, for Intense Exposure from Nuclear Bomb Blasts.

\section{New Types of Standard Reference} Materials (Radioactivity Standards) Developed for Environmental Protection. In response to needs for standards to calibrate instruments used in environmental protection and environmental matrix standards for realistic calibrations for environ- 
mental materials, new kinds of standards have been developed. In addition, standards for many new nuclides have been produced. The mixed radionuclide standards (about seven or nine radionuclide gamma-ray emitters in water solution) are extremely useful and widely bought because they enable the user to calibrate the efficiency vs. energy of his scintillation or solid state radiation detector in one measurement. Natural sediment standards (river bottom) are used to calibrate and check detectors for soil samples and gaseous standards for air measurements. These new standards have been extremely successfui and are making a major impact on the accuracy of environmental radioactivity measurements. 


\section{SUMMARY AND CONCLUSIONS}

The NBS Institute for Basic Standards exists to provide the central basis for a complete and consistent system of physical measurements in this country, to coordinate that system with those of other nations, and to provide essential services that will allow accurate and uniform physical measurements throughout the Nation's scientific community, industry, and commerce. The 1972-75 Study of the National Measurement Sys tem represents an effort to comprehend the totality of the clientele system that the Institute exists to support. Such comprehensive understanding is necessary if the Institute is to optimize its program.

The national system for physical measurements involves every individual and every organization performing measurements. The act of measurement is estimated to require perhaps six percent of the total gross national product, or some $\$ 90$ billion annually. In contrast, the NBS Institute for Basic Standards employs some 850 people and has an annual operating budget of around $\$ 45$ million. Deploying limited resources with care in support of such a massive system is necessary.

At the conclusion of any study of this kind, the question naturally arises, "What is different in your program or operations as a result of this study?"

* The most important difference is a major increase in cwareness of the measurement needs 0 : this country, on the part of a signi icart number of serior NBS staff members. This increase in cawareness of needs has ied to a suistantial improvement in the soupling of "BS progrons with user needs, or a troai front, and the establishment of new iissemination mechanisms for NBS interac: ions with measurement needs in the field.

Examples of this broadly improved coupling include participation on a continuing basis in the International Machine Tool Show, via an NBS exhibit, beginning in 1974; receipt of some 12,000 questionnaires from users to provide the basis for decisions regarding continuation and discontinuation of the services of NBS time and frequency radio stations; joining by NBS of the International Institute for Production Engineering Research, for liaison on surface finish problems; NBS leadership in U.S. participation in the International Organization for Legal Metrology; NBS sponsorship in February 1974 of a conference on "Flow Measurements as Related to National Needs;" use of a Delphi study to establish U.S. needs for vacuum measurement standards; a 1974 workshop on critical measurement needs and standards for modern electronic instrumentation; stimulation by NBS of the creation of the Council for Optical Radiation Measurements; establishment of working relationships with the Council on Color and Appearance; development of contacts between the NBS atomic and molecular physics groups and industrial users; a wide range of NBS activities in the ionizing radiation area; and coordinated voluntary standards participation interaction with regulatory agencies prior to the promulgation of mandatory standards.

* Reciprocally, people outside of NBS are more coware of NBS' interest and capability to serve, and are making more effective use of NBS.

Most of the examples just cited also apply here. For instance, some 4000 industry representatives visited the NBS booth at the September 1974 International Machine Tool Show, 460 of which requested over 1300 specific technical reports. The Council on Optical Radiation Measurements has generated a report "Pressing Problems and Projected National Needs in Optical Radiation Measurements-- A Consensus of Services Desired of NBS." Examples of a different kind include the training courses in pressure measurement developed for U.S. Navy technical personnel and offered by NBS to all comers; the 1976 Symposium at NBS/Gaithersburg of the National Conference of Standards Laboratories entitled "The National Measurement System--Today and Tommorrow, an Anniversary Review of our national industrial measurement system" for which the present writer was Associate Chairman: establishment of contact by the NBS far ultraviolet radiometry group with a wide variety of users of ultraviolet radiation with whom we had little, if any, contact before this study, plus reprogramming of effort to meet the needs of this group; and recognition by the Nuclear Regulatory Commission, the Energy Research and Development Administration, and the Environmental Protection Administration of the central role of NBS in the ionizing radiation measurements field.

* The study has had a number of specific progronmatic impacts:

Establishment of the NBS program for measurement problems associated with special (fissionable) nuclear materials, including identification of a Program Manager for Nuclear Safeguards Measurements, has been the largest single example to date of new pro- 
grams undertaken as a result of this study. It is also the major item receiving support from the Department of Commerce for expanded funding for the Institute in future Federal budgets. It has backing from the Nuclear Regulatory Commission, ERDA, the State Department, and industry.

Among the proposed major program efforts in FY 78 that are a direct result of this study and its immediate predecessors are the following:

1. Work toward establishment of a permanent satellite time and frequency service, including joint studies with NASA.

2. Development of non-destructive optical methods for calibration of surface roughness.

3. Provision of traceability to national standards of mass for dynamic weighing devices used, for example, for weighing meat in packing plants.

4. Participation with medical standards authorities in writing instrument specifications based upon results of NBS medical thermometry research.

5. Provision of needed thermodynamic data on methane and methane-hydrocarbon mixtures for the liquified natural gas and natural gas processing industries, which data will also play a key role in the development of predictive methods for fluid mixtures.

6. Extension of laser interferometry to permit determination of the volume of liquified natural gas tanks to the precision needed for international exchange.

7. Characteristics of dielectric insulation for underground superconducting electric power transmission lines.

8. New methods for characterizing analogto-digital and digital-to-analog converters.

9. Development of a sampling altemating current voltmeter for low frequency (les. than one hertz), low-level voltages encountered as outputs from vibration testing transducers.

10. Extension of capabilities for testing the susceptibility of components and electric systems to high frequency electromagnetic interference.

11. Measurement Assurance Program for users of NBS-developed near-field antenna scanning techniques.

12. Measurement of sound transmission through floor/ceiling assemblies or exterior walls of buildings.

13. Guidelines for the measurement of ultrasonic instrument parameters, to establish uniformity in instrumentation.

14. Creation of a spectroradiometer with an uncertainty significantly less than one percent for determining solar energy variations over long (e.g., ten year) periods of times, to help understand environmental changes.
15. Development of spectral reflectance and transmittance reference instruments needed for remote sensing of earth resources from aircraft and satellites.

16. Development of transfer-standard ultraviolet detectors for fusion energy programs.

17. Creation of a laser Measurement Assurance Program for high power industrial type lasers.

18. Completion of a study of requirements for regional calibration laboratories for the ionizing radiation field.

* The priorities defined in the fall of 1976 for the Institute for Basic Standards are a direct outgrowth of and completely consistent with the conclusions of this study of the national measurement system.

- Measurement standards and services required

for technology regulation

- Nuclear fuel safeguards

- Ionizing radiation

- Optical radiation

- Acoustical radiation

- Time domain measurements and standards (automated measurements and systems, communications, control)

- Coordinated modeling and measurement of critical properties of matter.

* The specific Institute program expansion objectives likewise follow directly from the study:

- Nuclear safeguard measurements

- Ionizing radiation measurements

- therapeutic dosimetry

- transfer standards for state programs

- U.V. measurements

- atmospheric modification

- industrial and medical applications

- Noise

- EPA, OSHA, DOT requirements

- building technology

- Mathematical methods

- sampling methods

- statistical methods

- mathematical models

- Electrical measurements for power transmisssion and distribution

- Methods of physical measurements for air and water quality

- Time resolved measurements for atomic and molecular energy systems.

* Similarly, the current vision of the conceptual features of the future Institute for Basic Stcondards has been substantially molded by the results of this study:

- Discipline dominated organization for generation of services - similar to present. 
- Specialized offices at Institute level for programmatic management of outputs to major communities of need and for urgent national problems.

- Continuing emphasis on R\&D for

- realization of basic units

- methods to transfer units

- methods of measurement

- properties of matter

- Emphasis on new programs for

- architectural development of measurement system

- stimulating growth of external institutional capabilities

- Increasing involvement in

- recognizing new needs for measurement which are national in scope

- planning coordinated multi-agency programs for meeting such needs

- Increasing involvement in legislative processes which generate measurement needs

- committee staff assistance

- impact statements

- expert testimony as appropriate

- Declining involvement in long established

- standards for highly derived units routine measurement services

- Increasing liaison at high management levels of federal agencies which generate measurement needs.

- Greater balance in generation of user specialized publications.

- Industrial measurements traceable to national standards (IBS) through hierarchical systems of Measurement Assurance Programs.

- Commercial measurements traceable to national standards (IBS) through states along present lines.

- State and/or regional capabilities for measurement services involving regulated quantities.

A question that is more difficult to answer is "How many of the results of the stuin would have come about in any case, whetiner or rot the study had been under tcienen?" Obviously, the study built upon earlier and on-going efforts that would have had significant effects in any case. Further, many of the conclusions reached were sufficiently inescapable that they would have been forced upon this Institute sooner or later, no matter what we did. Nevertheless, it seems fair to say that tile stum has played a maior role in supportir. the Institute to comprehend national measuremert needs and its role in meeting them $\therefore r$ : comprehensive and integrated fashion that would not have been achieved by the earlier, piecemeal efforts, or by any pattern or merely responding to demands thrust upon us from outside. The National Measurement System Study has established a prototype method of strategic planning, that has become a part of the normal way that the divisions of the Institute for Basic Standards do their long range planning. It has generated enlightenment regarding the importance of doing a total "market analysis", on both retrospective and forward-looking bases, rather than only fragmented studies with a specific, usually short range, "selling" orientation.

The microstudies have been used in connection with many reprogramming decisions at all levels within the Institute for Basic Standards, and the microstudy reports have been sources of information for these and other purposes. These studies have provided reassurance to Institute management regarding the adequacy of a number of loweffort sustaining programs; the most notable example of such reassurance is in the area of mass and density measurements, where a few manyears of effort support a tremendous portion of the measurement system. They have led to creation of new institutional mechanisms, most notably the Council for Optical Radiation Measurements.

The measurement system study concept and results are being integrated into NBS interactions with Federal, state, and local governmental units. For instance, it is clear that proliferation of measurement responsibilities, especially in the newer health and environmental regulatory agencies at state and local governmental levels, is creating situations within many states where substantial improvements in efficiency of measurement-related governmental activities can be effected if the state measurement system can be seen as a whole and if conscious steps can be taken to promote cooperation and mutual support among different segments of the system. California has been a leader here, through its Measurements Advisory Committee.

The Study as such has drawn to a close, and has been metamorphosized into a basic element in the long range planning of the Institute and its Divisions. Given the current definition of the mission of the Institute--which can be simply summarized as to support and strengthen the national measurement system--all long range or strategic planning in the Institute must henceforth be able to answer the obvious questions: What is the state of the System? What are its needs? How will the proposed efforts support and strengthen the System? How will we disseminate the results of our work? What altemative uses could be made of the resources required, and would the pay-off for the System be higher for any of these alternatives? 
The study has achieved its objectives. It has affected a drastic speedup in the Institute's ability to describe the rationale for its programs. It has effected an acrossthe-board analysis of the entire scope of the Institute's measurement and dissemination concerns. It has provided information to management to improve the allocation of limited resources, and changes in allocation of resources have occurred at all managerial levels. It is providing support to Institute efforts to obtain new resources, by demonstrating that the Institute has a clear concept of its responsibilities. It has both been an effective tool in itself in planning for the, future, and has established a continuing mechanism for such planning. It is leading to improvement of the architecture of our evolving National Measurement System. 
[1] Huntoon, R. D., Concept of a national measurement system, Science 158, 67-71 (6 0ct. 1967).

[2] Corruccini, R. J., The Role of Basic Standards in the Economy, NBS internal working document, generated in response to the request of Apri] 12, 1972, by the Assistant Secretary of Commerce for Administration, 41 pages (JuTy 3, 1972).

[3] Cochrane, R. C., Measures for Progress--A History of the National Bureau of Standards, Nat. Bur. Stand. (U.S.), Misc. Publ. 275, 728 pages (1966).

[4] Silverman, S., The national measurement systeri--a concept to assist the private sector, Mater. Res. Stand. 9, No. 10, 11-14 (Oct. 1969).

[5] Ambler, E., Program to insure that IBS capability is used in the field to the maximum degree of effectiveness and to develop new capability where necessary, NBS internal memorandum, directed to IBS Division Chiefs and Dr. Leiss, 6 pages (May 5, 1972).

[6] Ambler, E., Progress of Study of the National Measurement System, NBS internal memorandum directed to IBS Division Chiefs, 6 pages (March 23, 1973).

[7] Risley, A. S., The national measurement system for time and frequency, Nat. Bur. Stand. (U.S.), Spec. Pub1. 445-1, 76 pages (May 1976).

[8] Lazar, J. W., and Bach, R. L., The national measurement system for length and related dimensional measurements, Part I., NBSIR 75-926, part I, 113 pages (Aug. 1976).

[9] Ramboz, J. D., The national measurement system for length and related dimensional measurements, Part II: Vibration and shock. NBS intemal working document (in preparation).

[10] Young, R. D., The national measurement system for surface finish, NBSIR 75-927, 48 pages (July 1976).

[11] Pontius, P. E., Simpson, J. A., and Whetstone, J. R., The national mass, volume, and density measurement system NBSIR 75-928 (in preparation).

[12] Marlowe, D. E., A study of the national force measurement system, NBSIR 75-929 (June 1975).

[13] Haight, W. C., Klebanoff, P. S., Ruegg, F. W., and Kulin, G., The national fluid flow measurement system, HBSIR 75-930 (Aug. 1976).

[14] Heydemann, P. L. M., The national measurement system for pressure, NBSIR 75-93] (Aug. 1976).

[15] Schooley, J. F., The national measurement system for temperature, NBSIR 75-932, 58 pages (Aug. 1976).

[16] Wexler, A., A study of the national humidity and moisture measurement system, NBSIR 75-933, 51 pages (Aug. 1975).

[17] Klein, M., The national measurement system for the thermodynamic properties of fluids, NBSIR 75-934 (in preparation).

[18] Flynn, T. M., The national measurement system for cryogenics, NBSIR 75-825, 75 pages (Oct. 1975).

[19] Belecki, N. B., Dunfee, B. L., and Petersons, 0., Electricity division study of the national measurement system, NBSIR 75-935 (in preparation).

[20] Reis, F. X., and Anson, W. J., The national electromagnetic measurement system, NBS internal working document, 72 pages (March 31, 1975).

[21] Kamper, R. A., et al., The national electromagnetic measurement system, NBSIR 75-936 (in preparation).

[22] Hudson, P. A. The national measurement system for medical ultrasonics, NBSIR 75-937, 19 pages (Feb. 1976).

[23] Pallett, D. S., The national measurement system for acoustics, NBSIR 75-937 [Feb. $1977]$.

[24] Kostkowski, H. J., The national measurement system for radiometry and photometry, NBSIR 75-939.

[25] Venable, W. H., Jr., The national measurement system for spectrophotometry, NBSIR 75-940 (in preparation).

[26] 0tt, W. R., The national measurement system for far ultraviolet radiometry, NBSIR 75-941 (in preparation).

[27] Swyt, D. A., The national measurement system for optics, NBSIR 75-942, 60 pages (Aug. 1976).

[28] Mahler, R. J., The national measurement system for lasers, NBS internal working document, 48 pages (May 1975).

[29] Cooper, J. W., Phelps, A. V., and Smith, S. J., The national measurement system for the physical properties of atoms and molecules, NBSIR 75-944 (Sept. 1976).

[30] Powell, C. J., The national measurement system for surface properties, NBSIR 75945 [Feb. 1977].

[31] Caswell, R. S. , The national measurement system for ionizing radiation, NBSIR 75-946 (in preparation). 
[32] Seed, J. R., and Pawlik, P. U., National measurement system - NCSL, the value of making measurements, preprint of paper prepared for NCSL Newsletter (Dec. 12, 1973 ).

[33] Pawlik, P. U., Economic dimensions of the national measurement system, NBS internal working document, 350 pages (1973).

[34] Morgan, H. E., The economic cost of physical measurements, NBS internal working document (June 30, 1974).

[35] Poulson, B. W., editor, Economic analysis of the national measurement system, NBSIR 75-948 (in preparation).

[36] Sangster, R. C., Structure and functions of the national measurement system, NBSIR 75-949 (in preparation).

[37] MCNish, A. G., The basis of our measuring system, Proc. IRE 47, 636-43 (May 1959 ).

[38] Huntoon, R. D., Standards for the future, preprint, Annual Spring Conference, American Standards Association and Standards Engineers Society, Boston, Mass., 18 pages (May 24-24, 1962).

[39] Huntoon, R. D., Role of NBS in the National Measurement System, internal NBS memorandum, to list (Aug. 24, 1965).

[40] Scientists discuss NBS role in the national measurement system, Nat. Bur. Stand. (U.S.), press release, TRG-6441, 5 pages (0ct. 5, 1965).

[41] Huntoon, R. D., The basis of our measurement system, Physics Teacher 4 , 113-20 (Mar. 1966).

[42] Eskite, W. H., Jr., Studies of the national measurement system, final report on Department of Commerce Science and Technology Fellowship Program assignment, NBS internal working document (July 1, 1966).

[43] Measurement, Pacemaker of American Economic Growth, booklet, U.S. Dept. of Commerce (U.S. Govt. Print. Off., Washington, D.C., 1966).

[44] Astin, A. V., Program memorandum and program and financial plan for Commerce Program Category V. The Physical Measurement System, NBS memorandum to Dr. J. Herbert Hollomon, Acting Undersecretary for Commerce (June 12, 1967).

[45] Huntoon, R. D. . The measurement system of the United States, Proc. 1966 Standards Laboratory Conference, Nat. Bur. Stand. (U.S.). Misc. Pub1. 291, 89-98 (July 13, 1967).

[46] Gentilini, A. V., Summary of national measurement system, NBS internal memorandum to members of motion picture committee, 35 pages (May 3, 1968).

[47] Huntoon, R. D., Extending the measurement infrastructure to meet the needs of developing establishments, NBS internal working document, 55 pages (July 1971).

[48] Roberts, R. W., A close look at the national measurement system, booklet, talk given at NBS, Gaithersburg, Md. (Nov. 14, 1973).

[49] Brief history of measurement systems, Nat. Bur. Stand. (U.S.), Spec. Publ. 304 A, 4 pages (Sept. 1974).

[50] Astin, A. V., Standards of measurement, Sci. Am. 218, No. 6, 50-62 (June 1968).

[51] Jefferson. Thomas, Secretary of State, Plan for establishing uniformity in the coinage, weights, and measures of the United States, Report of the First Congress, second session, No. 15, pp. 13-30 (July 4, 1790), published in American State Papers, Class X, Miscellaneous, v. I, p. 13 (Gales and Seaton, Washington, D. C., 1834).

[52] Adams, John Quincy, Secretary of State, Report of the Secretary of State upon weights and measures, 245 pages (J. D. Moore, Feb. 22, 1821), published in American State Papers, Class X, Miscellaneous, V. II, P. 656 (Gales and Seaton, Washington, D.C., 1834).

[53] Jones, S. A., Weights and measures in Congress. Historical summary covering the period of the Continental Congress to and including the adoption of the joint resolutions of 1836 and 1838, Nat. Bur. Stand. (U.S.), Misc. Publ. M122 (Mar. 1936).

[54] Moreau, H. , THe genes is of the metric system and the work of the International Bureau of Weights and Measures, J. Chem. Educ. 30, 3-20 (Jan. 1953).

[55] Smith, R. W. . The Federal Basis for weights and measures, Nat. Bur. Stand. (U.S.), Circ. 593, 23 pages (June 1958).

[56] Irwin, K. G., Romance of Weights and Measures, 144 pages (Viking Press, New York, N.Y., 1960).

[57] McNish, A. G., Fundamentals of measurement, Electro-Technology (Beverly Shores, Indiana), 113-28 (May 1963).

[58] Judson, L. V., Weights and measures of the United States, a brief history, Nat. Bur. Stand. (U.S.), Misc. Publ. 247, 30 pages (Oct. 1963).

[59] Astin, A. V., Away from arbitrary man-made standards toward a system based on physical constants, Res. Dev. 16, No. 10, 68-69 (Oct. 1965).

[60] Huntoon, R. D., Status of the national standards for physical measurement, Science 150 , 169-78 (8 0ct. 1965). 
[61] Howlett, L. E., International basis for uniform measurement, Science 158, 72-74 ( 6 Oct. 1967).

[62] Zupko, R. E., A Dictionary of English Weights and Measures from Anglo-Saxon Times

to the Nineteenth Century (Univ. Wisconsin Press, Madison, Wisc., 1968).

[63] Stiehler, R. D. , History of measurement and the SI units, Mater. Res. Stand. $\underline{9}$, No. 6, 14-18 (June 1969).

[64] Ambler, E., Measurement standards, physical constants, and science teaching, Science Teacher 38, No. 8, 63-71 (Nov. 1971).

[65] International Standard ISO 1000, SI units and recommendations for the use of their multiples and of certain other units, first edition -- 1973-02-01 (International Organization for Standardization, 1973).

[66] Page, C. H., and Vigoureaux, P., ed., The International System of Units (SI), Nat. Bur. Stand. (U.S.), Spec. Publ. 330, 49 pages (July 1974).

[67] Klein, H. A., The World of Measurements (Simon and Schuster, New York, N.Y., 1974).

[68] Page, C. H., and Vigoureaux, P., ed., The International Bureau of Weights and Measures, translation of the BIPM centennial volume, Nat. Bur. Stand. (U.S.), Spec. Publ. 420,

256 pages (May 1975).

[69] NBS guidelines for use of the metric system, Nat. Bur. Stand. (U.S.), Letter Circ. 1056, 4 pages (rev. Aug. 1975).

[70] Stiehler, R. D., U.S. Metric Study Interim Report: Engineering Standards, Nat. Bur. Stand. (U.S.), Spec. Pubi. 345-11, 264 pages (July 1971).

[71] Huntoon, R. D., et al., U.S. Metric Study Report: International Standards, Nat. Bur. Stand. (U.S.), Spec. Pub1. 345-1, 157 pages (Dec. 1970).

[72] Slattery, W. J., ed., An Index of U.S. Voluntary Engineering Standards, Nat. Bur. Stand. (U.S.), Spec. Pubi. 329, 1000 pages (March 1971).

[73] Slattery, W. J., ed., An Index of U.S. Voluntary Engineering Standards, Supplement 1 , Nat. Bur. Stand. (U.S.), Spec. Publ. 329, Supp1. 1, 459 pages (Dec. 1972).

[74] Slattery, W. J., ed., An Index of U.S. Voluntary Engineering Standards, Supplement 2, Nat. Bur. Stand. (U.S.), Spec. Publ. 329, Suppl. 2, 472 pages (May 1975).

[75] Kushner, L. M., We have decided to become more active at the policy level in voluntary standardization activities, Mater. Res. Stand. 12, No. 5, 13-14 (May 1972).

[76] Andrus, W. E., A focus for the Bureau and a 11 voluntary standardization organizations, Mater. Res. Stand. 12, No. 5, 15-17 (May 1972).

[77] Specifications, Tolerances, and Other Technical Requirements for Commercial Weighing and Measuring Devices, Nat. Bur. Stand. (U.S.), Handb. 44, 4th edition (Nov. 1971).

[78] Chapter 27, Photographic equipment and supplies, Chapter 36, Metalworking machinery and tools, Chapter 37, Instruments for measurement, analysis and control, and Chapter 38. Medical and dental instruments and supplies. U.S. Industrial Outlook 1975 with Projections to 1980. pp. 261-65, 347-56,357-71, and 372-79 (U.S. Dept. Commerce, U.S. Govt. Print. Off., Washington, D.C., 1974).

[79] Guide to scientific instruments, Science 190, No. 4216A (25 Nov. 1975).

[80] Mason, H. L., and Lloyd, I. M., Special technical facilities at the National Bureau of Standards, Nat. Bur. Stand. (U.S.), Spec. Pub1. 413, 1976 edition, 50 pages (Mar. 1976).

[81] Brady, E. L., and Wallenstein, M. B., The National Standard Reference Data System, Science 156, 754-62 (12 May 1967).

[82] Brady, E. L., The National Standard Reference Data System, Mater. Res. Stand. 9 , No. 10, 19-21 (Oct. 1969).

[83] Rossmassier, S. A., ed., Critical evaluation of data in the physical sciences--a status report on the National Standard Reference Data System, June 1972, Nat. Bur. Stand. (U.S.), Tech. Note 747,79 pages (Nov. 1972).

[84] Rossmassier, S. A., ed., Critical evaluation of data in the physical sciences--a status report on the National Standard Reference Data System, Apri7 1975, Nat. Bur. Stand. (U.S.), Tech. Note 881, 53 pages (Sept. 1975).

[85] Cali, J.P., et al., The role of Standard Reference Materials in measurement systems, Nat. Bur. Stand. (U.S.), Monogr. 148, 54 pages (Jan. 1975).

[86] Meinke, W. W. The NBS Standard Reference Materials program: past, present, and future, Mater. Res. Stand. 9 , No. 10, 15-18 (Oct. 1969).

[87] Gorozhanina, R. S., Freedman, A. Y., and Shaievitch, A. B., Standard Reference Materials: Standard Samples Issued in the USSR, booklet, 81 pages (Publishing House of Standards, Moscow, USSR, 1969). Translated by M. C. Selby as Nat. Bur. Stand. (U.S.), Spec. Publ. 260-30, 86 pages (June 1971).

[88] Hoffman, J. D., IMR emphasizes accurate measurements and standards for materials, Mater. Res. Stand. 12, No. 5, 24-33, 71 (May 1972). 
[89] Roberts, R. W. , The other face of the measurement base, remarks at the Pittsburgh Conference on Analytical Chemistry and Applied Spectroscopy, Cleveland, Ohio, March 3, 1975, Nat. Bur. Stand. (U.S.), booklet, 24 pages (Mar. 1975).

[90] Catalog of NBS Standard Reference Materialis, 1975-76 edition, Nat. Bur. Stand. (U.S.), Spec. Pub 1. 260-1975-76 catalog, 90 pages (June 1975).

[91] Standard Reference Materials, 1975 price Tist, Nat. Bur. Stand. (U.S.), Spec. Publ. 260, supplement, 17 pages (1975).

[92] Lance, H. W. The Nation's electronic standards program: Where do we now stand?,

IRE Trans. Instrum. I-9, 94-100 (Sept. 1960).

[93] McNish, A. G., and Cameron, J. M., Propagation of error in a chain of standards,

IRE Trans. Instrum. I-9, 101-4 (Sept. 1960).

[94] Hachey, L. E., Better measurements through user feedback, ISA J 8 , No. 2, 60-63 (Mar. 1961).

[95] Selby, M. C., et al., A program to provide information on the accuracy of electrical measurements, Proc. IEEE 51, 569-74 (April 1963).

[96] Eisenhart, C., Realistic evaluation of the precision and accuracy of instrument calibration systems, J. Res. Nat. Bur. Stand. (U.S.), 67C (Eng. and Instr.), No. 2, 161-87 (April-June, 1963).

[97] Huntoon, R. D., and Wildhack, W. A., Planning for better measurement accuracy, ISA J 12. No. 1, 57-60 (Jan. 1965).

[98] Wi idhack, W. A., Powell, R. C., and Mason, H. L. Accuracy in measurements and calibrations, 1965, Nat. Bur. Stand. (U.S.), Tech. Note 262, 151 pages (June 1965).

[99] Powel1, R. C., Accuracy in electrical and radio measurements and calibrations, 1965, Nat. Bur. Stand. (U.S.), Tech. Note 262-A, 93 pages (June 1965).

[100] Wildhack, W. A., Mason, H. L., and Powers, R. S., Jr., Accuracy charts for RF measurements, Proc. IEEE 55, 1056-63 (June 1967).

[101] Eisenhart, C., Expression of the uncertainties of final results, Science 160, 1201-4 (14 June 1968).

[102] Precision Measurements and Calibration, Nat. Bur. Stand. (U.S.), Spec. Publ. 300, 12 volumes (1968).

[103] Simson, B. G., and Radlinski, R. W., The accuracy of air tower pressure gages in suburban Washington, D.C., Nat. Bur. Stand. (U.S.), Tech. Note 512, 10 pages (Dec. 1969).

[104] Calibration and test services of the National Bureau of Standards, Nat. Bur. Stand. (U.S.), Spec. Publ. 250-1970 edition (Dec. 1970).

[105] Proceedings of the 1972 Joint Measurement Conference, June 21-23 (Instrum. Soc. Am. , Pittsburgh, Pa., 1972).

[106] Huntoon, R. D., Lichtenstein, S., and Finger, G. A., The National Bureau of Standards prepares for the 1970's, Scjence 165,867-74 (29 Aug. 1969).

[107] Kushner, L. M., The NBS contributions to technological measurements and standards, Mater. Res. Stand. 2, No. 10, 8-10 (0ct. 1969).

[108] Science Policy Research Division, Library of Congress: National Bureau of Standards, A Review of Its Organization and Operations: A Study Prepared for the Subcomittee on Science, Research, and Development of the Committee on Science and Astronautics, U.S. House of Representatives (U.S. Govt. Print. Off., Washington, D.C., Sept. 8, 1971).

[109] National Bureau of Standards Oversight Hearings, Hearings before the subcomittee on Science, Research, and Development of the Committee on Science and Astronautics, U.S. House of Representatives, Sept. 16, 21-23, 28, 1971, 387 pages (U.S. Govt. Print. Off., Washington, D.C., 1971).

[110] Branscomb, L. M., to help advance our Nation's science \& technological capabilities for the greatest public benefit, Mater. Res. Stand. 12, No. 5, 8-12 (May 1972).

[111] Willenbrock, F. K., We can never afford to be technically wrong, Mater. Res. Stand. 12. No. 5, 34-36, 71-72 (May 1972).

[112] National Bureau of Standards, Nat. Bur. Stand. (U.S.), Spec. Publ. 397,64 pages (June 1974).

[113] National Bureau of Standards annual report: Fiscal Year 1974, Nat. Bur. Stand. (U.S.), Spec. Publ. 418, 32 pages (Mar. 1975).

[114] National Bureau of Standards at a Glance, Nat. Bur. Stand. (U.S.), book let, 46 pages (Aug. 1975).

[115] National Bureau of Standards annual report: FY 1975, Nat. Bur. Stand. (U.S.), Spec. Pub1. 437, 32 pages (Dec. 1975).

[116] Ambler, E. Looking back: a 75 year preview of things to come, an address on the occasion of the 75th anniversary of the National Bureau of Standards, Nat. Bur. Stand. (U.S.), book let, 28 pages (March 4, 1976). 
[117] The National Conference on Weights and Measures, its organization and procedures, booklet, 10 pages (U.S. Dept. Commerce, about 1973).

[118] Mission, Office of Weights and Measures, U.S. Department of Comerce, National Bureau of Standards, booklet, 6 pages (about 1973).

[119] The weights and measures men, a pamphlet for consumers (National Conference on Weights and Measures, about 1973).

[120] Koeser, R. L., ed., Report of the 54th National Conference on Weights and Measures 1969 Nat. Bur. Stand. (U.S.), Spec. Publ. 318, 270 pages (Nov. 1969).

[121] Bell, F. C., and Wollin, H. F., ed., Report of the 55th National Conference on Weights and Measures 1970, Nat. Bur. Stand. (U.S.), Spec. Pub1. 342, 315 pages (Apri1 1971).

[122] Hatos, S. L., U.S. Metric Study Interim Report: Commercial Weights and Measures, Nat. Bur. Stand. (U.S.), Spec. Pub1. 345-3, 116 pages (July 1971).

[123] Bell, F. C., and Wollin, H. F., ed., Report of the 56 th National Conference on Weights and Measures 1971, Nat. Bur. Stand. (U.S.), Spec. Publ. 358, 252 pages (Mar. 1972).

[124] Bell, F. C., and Wollin, H. F., ed., Report of the 57th National Conference on Weights and Measures 1972, Nat. Bur. Stand. (U.S.), Spec. Pub1. 379, 216 pages (May 1973).

[125] Wilson, S. J., and Smith, R. N., ed., Report on the 58th National Conference on Weights and Measures 1973, Nat. Bur. Stand. (U.S.), Spec. Pub1. 291, 208 pages (May 1974).

[126] National Directory of Weights and Measures Personnel (Dept. Commerce, NBS, May 1974).

[127] Minnick, D. J., National census of weights and measures personnel, preliminary report, Nat. Bur. Stand. (U.S.) (June 1974).

[128] Edgerly, S. J., ed., Report of the 59th National Conference on Weights and Measures 1974, Nat. Bur. Stand. (U.S.), Spec. Pub1. 407, 284 pages (June 1975).

[129] Weights and measures directory, list of state, commonwealth, district, and major local weights and measures cffices of the United States, Nat. Bur. Stand. (U.S.), directory (Mar. 1976).

[130] Edgerly, S. J., ed., Report of the 60th National Conference on Weights and Measures 1975, Nat. Bur. Stand. (U.S.), Spec. Publ. 442, 272 pages (May 1976).

[131] National Conference of Standards Laboratories, booklet, 8 pages (undated, app. 1975).

[132] A Directory of Standards Laboratories (National Conference of Standards Laboratories, 1976).

[133] Van de Houten, J., The standards laboratory as an element in the national measurement system, Preliminary report at 22nd Annual Meeting of the Standards and Metrology Division, American Ordnance Association (April 12-13, 1967).

[134] Mason, H. L., ed., Making Valuable Measurements (Proc. 1968 Standards Laboratory Conference, NBS, Boulder, Colo., Aug. 26-29, 1968), Nat. Bur. Stand. (U.S.), Spec. Pub1. 313, 177 pages (May 1969).

[135] The National Conference of Standards Laboratories, ASTM Standardization News 2 , 18-22 (Nov. 1974).

[136] International quality assessment, ASTM Standardization News 2, 23-28 (Nov. 1974).

[137] Sangster, R. C., Transactions Matrix description of the national system of physical measurements, NBSIR 75-943, 88 pages (Aug. 1976).

[138] Porat, M. U., Defining an information sector in the U.S. economy, second year project report (Institute for Communication Research, Stanford University, Stanford, Calif., Nov. 1974).

[139] Noble, D. E., The challenge of intelligent decision making, Proc. Rome Air Development Center 20th Anniversary Celebration: The Next Twenty Years--the Promise and the Challenge, pp. 65-74 (Rome Air Development Center, June 9-11, 1971).

[140] Ambler, E., Keynote address to National Conference of Standards Laboratories Syniposiun (Oct 6, 1976).

[141] Ambler, E., A major innovation is our Measurement Assurance Program, Mater. Res. Stand. 12. No. 5, 18-23 (May 1972).

[142] Nicodemus, F. E., ed., Self-study manual on optical radiation measurements: Part 1-concepts, Chapters 1-3, Nat. Bur. Stand. (U.S.). Tech. Note 910-1, 93 pages (Mar. 1976).

[143] Jones, R. N., The Measurement of Lumped Parameter Impedance: a Metrology Guide,

Ed. W. J. Anson, Nat. Bur. Stand. (U.S.), Monogr. 141, 211 pages (June 1974).

[144] Arthur, M. G. The Measurement of Noise Performance Factors: A Metrology Guide, Ed. W. J. Anson, Nat. Bur. Stand. (U.S.), Monogr. 142, 202 pages (June 1974).

[145] America joins a metric world, Nat. Bur. Stand. (U.S.), Dimensions/NBS 60, No. 2, 6-9 (Feb. 1976).

[146] Langenberg, D. N., and Taylor, B. N., ed., Precision Measurements and Fundamental Constants, Nat. Bur. Stand. (U.S.), Spec. Pubi. 343, 543 pages (Aug. 1971).

[147] Cohen, E. R., and Taylor, B. N., Specifications of the physical world: new values for the fundamental constants, Nat. Bur. Stand. (U.S.), Dimensions/NBS, 5 pages (Jan. 1974). 
[148] Kendrick, J., Postwar Productivity Trends in the United States 1948-1969 (Columbia University Press for the National Bureau of Economic Research, New York, N.Y., 1973).

[149] U. S. Department of Labor, Bureau of Labor Statistics, Handbook of Labor Statistics (1973).

[150] Desimone, D. V., A Metric Anerica: A Decision Whose Time Has Come, Nat. Bur. Stand. (U.S.), Spec. Publ. 345, 188 pages (July 1971).

[151] What six firms found going metric: A lot easier and cheaper than expected, U.S. Hews and World Report, p. 114 (July 5, 1976).

[152] Richman, P., ed., Critical electrical measurement needs and standards for modern electronic instrumentation, report of a workshop sponsored by the National Bureau of Standards, Gaithersburg, Md., Sept. 23-24, 1974, Nat. Bur. Stand. (U.S.), Tech. Note 865, 74 pages (May 1975). 
NBS.IILA IREV. 7.73)

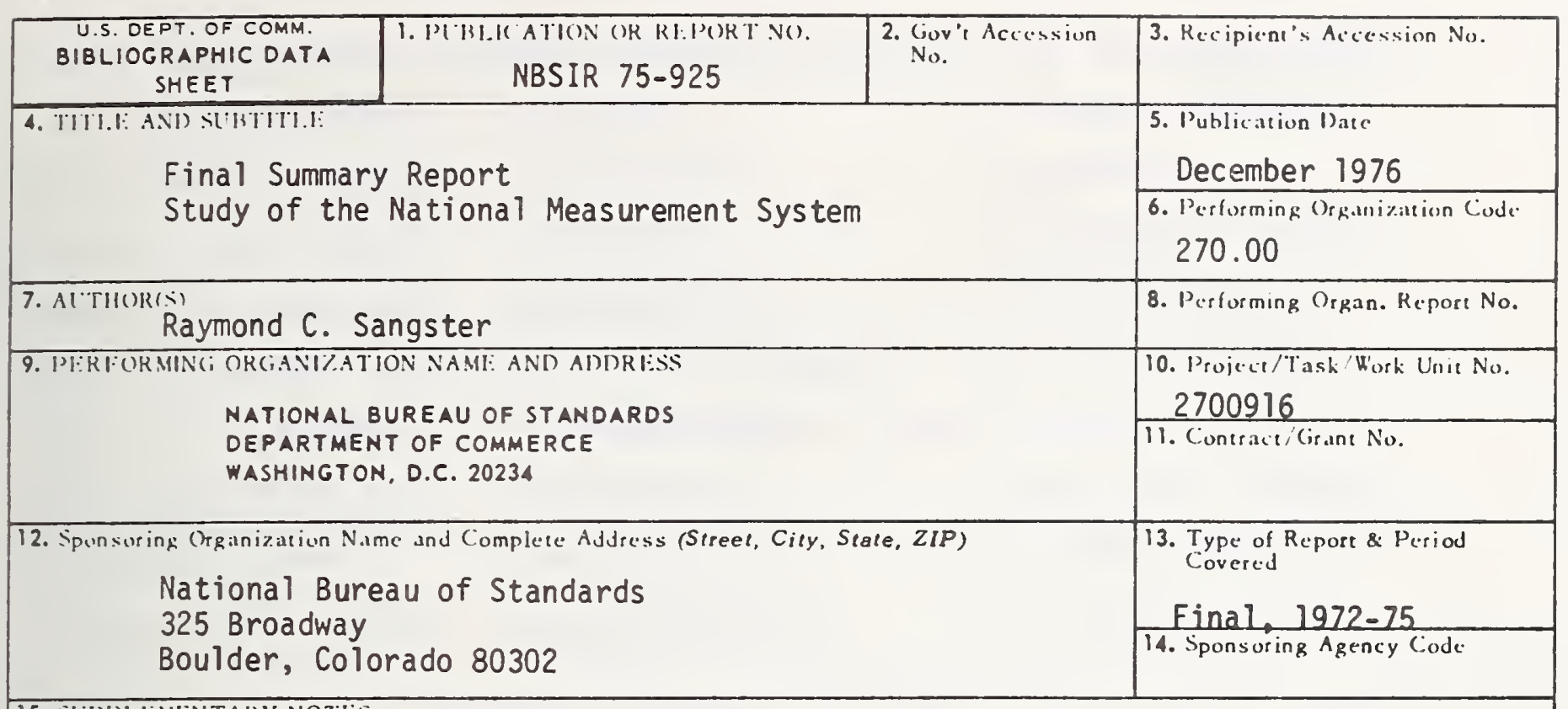

15. SLPPI.MENTARY NOTES

16. ABSTR.ACI (A 200-word or less factual summary of most significant information. If document includes a significant bibliography or literature survey. mention it here.) This is the summary report for the $1972-75$ NBS Study of the National Measurement System; i.e., the activities and mechanisms that provide physical measurement data for creation of objective, quantitative knowledge for use in our personal lives, society, science, and technology. It includes structural and economic overviews of the system and summarizes results of microstudies of specific measurement sectors. The structural model of the system has five levels: conceptual system, basic technical infrastructure, realized measurement capabilities, institutional dissemination and enforcement network, and end-use measurement activities. Transactions in the system have been described in a matrix format. Measurement-related activities account for about $6 \%$ of Gross National Product and pervade all economic sectors. Indicative cost-benefit analyses are described. Measurement sectors covered by 24 microstudies include time and frequency; mechanical, thermal, electrical, electromagnetic acoustic, and optical quantities, and ionizing radiation. Major system trends are toward increased complexity and integration, improved quality control and information resources, automation, metrication, and consolidation of the recent scientific revolution in metrology. Deficiencies exist in assurance of measurement quality, communication of needs and capabilities, missing structure in newer measurement fields, measurements for technical regulations, and measurements made with many newer transducers or under dynamic or adverse environmental conditions. NBS is the central measurements standards institution supporting our National Measurement System.

17. KEY WORDS (six to twelve entries; alphabetical order; capitalize only the first letter of the first key word unless a proper name; separaled by semicolons) Acoustics; economics of measurement; electrical quantities; electromagnetic quantities; ionizing radiation; measurement needs; measurement system structure; mechanical quantities; National Measurement System; optical quantities; thermal quantities; time and frequency.
18. AVAILABILITY
$\mathbf{X}$ Unlimited

For Official Distribution. Do Not Release to NTIS

[.7 Order From Sup. of Doc., U.S. Government Printing Office Washington, D.C. 20402, SD Cat. No. C13

X. Order From National Technical Information Service (NTIS) Springfield, Virginia 22 Is 1

\begin{tabular}{|l|c|}
\hline $\begin{array}{l}\text { 19. SECURITY CLASS } \\
\text { (THIS REPURT) }\end{array}$ & 21. NO. OF PAGES \\
UNCL ASSIFIED & 45 \\
\hline $\begin{array}{l}\text { 20. SECURITY CLASS } \\
\text { (THIS PAGE) }\end{array}$ & 22. Price \\
UNCLASSIFIED & $\$ 4.00$ \\
\hline
\end{tabular}



REQUEST CARD FOR REPORTS OF NATIONAL MEASUREMENT SYSTEM (NMS) STUDY (Circle No's wanted)

925 FINAL SUMMARY REPORT 929 FORCE

943 TRANSACTIONS IN NMS 930 FLUID FLOW

947 COLL. EXEC. SUMMARIES 931 PRESSURE

948 ECONOMIC ANALYSIS NMS 932 TEMPERATURE

949 STRUCTURE/FUNCTIONS NMS

345-1 TIME \& FREQUENCY

926 LENGTH \& DIMEN. MEAS.; 825 CRYOGENICS VIBRATION \& SHOCK

927 SURFACE FINISH

928 MASS, VOLUME, DENSITY
933 HUMIDITY \& MOISTURE

934 THERMOOYNAMICS OF FLUIDS

935 ELECTRICITY

936 ELECTROMAGNETICS
937 MECICAL ULTRASONICS

938 ACOUSTICS

939 RADIOMETRY/PHOTOMETRY

940 SPECTROPHOTOMETRY

941 FAR UV RADIOMETRY

942 OPTICS

944 PHYS. PROP. ATOMS/MOL.

945 SURFACE PROPERTIES

946 IONIZING RADIATION

REQUEST CARD FOR REPORTS OF NATIONAL MEASUREMENT SYSTEM (NMS) STUDY (Circle No's wanted)
925 FINAL SUMMARY REPORT
929 FORCE
937 MEDICAL ULTRASONICS
943 TRANSACTIONS IN NMS
930 FLUID FLOW
938 ACOUSTICS
947 COLL. EXEC. SUMMARIES
931 PRESSURE
939 RADIOMETRY/PHOTOMETRY
948 ECONOMIC ANALYSIS NMS
932 TEMPERATURE
949 STRUCTURE/FUNCTIONS NMS
933 HUMIDITY \& MOISTURE
940 SPECTROPHOTOMETRY
345-1 TIME \& FREQUENCY
934 THERMODYNAMICS OF FLUIDS
926 LENGTH \& DIMEN. MEAS.;
825 CRYOGENICS VIBRATION \& SHOCK
927 SURFACE FINISH
935 ELECTRICITY
941 FAR UV RADIOMETRY
928 MASS, VOLUME, DENSITY
936 ELECTROMAGNETICS
942 OPTICS
944 PHYS. PROP. ATOMS/MOL.
945 SURFACE PROPERTIES
946 IONIZING RADIATION

REQUEST CARD FOR REPORTS OF NATIONAL MEASUREMENT SYSTEM (NMS) STUDY (Circle No's wanted)

925 FINAL SUMMARY REPORT

943 TRANSACTIONS IN NMS

947 COLL. EXEC. SUMMARIES

948 ECONOMIC ANALYSIS NMS

949 STRUCTURE/FUNCTIONS NMS

345-1 TIME \& FREQUENCY

926 LENGTH \& DIMEN. MEAS.; VIBRATION \& SHOCK

927 SURFACE FINISH

928 MASS, VOLUME, DENSITY
929 FORCE

930 FLUID FLOW .

931 PRESSURE

932 TEMPERATURE

933 HUMIOITY \& MOISTURE

934 THERMODYNAMICS OF FLUIDS

825 CRYOGENICS

935 ELECTRICITY

936 ELECTROMAGNETICS
937 MEDICAL ULTRASONICS

938 ACOUSTICS

939 RADIOMETRY/PHOTOMETRY

940 SPECTROPHOTOMETRY

941 FAR UV RADIOMETRY

942 OPTICS

944 PHYS. PROP. ATOMS/MOL.

945 SURFACE PROPERTIES

946 IONIZING RADIATION 
FROM: NAME :

TITLE :

ORGANIZATION:

ADDRESS :

CITY/STATE:

COUNTRY/ZIP:

TO: PROGRAM INFORMATION OFFICE NATIONAL BUREAU OF STANDARDS

BOULDER, COLORADO, USA 80302

FROM: NAME :

Place

TITLE:

Stamp

Here

ORGANIZATION :

ADDRESS:

CITY/STATE :

COUNTRY/ZIP:

T0: PROGRAM INFORMATION OFFICE NATIONAL BUREAU OF STANDARDS BOULDER, COLORADO, USA 80302

FROM: NAME:

TITLE: Here

ORGANIZATION:

ADDRESS:

CITY/STATE :

COUNTRY/ZIP:

TO: PROGRAM INFORMATION OFFICE NATIONAL BUREAU OF STANDARDS BOULDER, COLORADO, USA 80302 

